Article

\title{
Synthesis and Antiviral Evaluation of (1,4-Disubstituted-1,2,3-Triazol)-(E)-2-Methyl-but-2-Enyl Nucleoside Phosphonate Prodrugs
}

\author{
Tuniyazi Abuduaini ${ }^{1}$, Vincent Roy ${ }^{1, *}\left(\mathbb{D}\right.$, Julien Marlet ${ }^{2}$, Catherine Gaudy-Graffin ${ }^{2}$, Denys Brand ${ }^{2}$, \\ Cécile Baronti ${ }^{3}$, Franck Touret ${ }^{3}{ }^{1}$, Bruno Coutard ${ }^{3}$, Tamara R. McBrayer ${ }^{4}$, Raymond F. Schinazi ${ }^{4}$ \\ and Luigi A. Agrofoglio 1,* \\ 1 Institute of Organic and Analytical Chemistry, CNRS UMR 7311, Universite d'Orléans, \\ F-45067 Orléans, France; tuniyazi.abuduaini@univ-orleans.fr \\ 2 Inserm U1259, Université de Tours, 37032 Tours, France; julien.marlet@univ-tours.fr (J.M.); \\ catherine.gaudy-graffin@univ-tours.fr (C.G.-G.); denys.brand@univ-tours.fr (D.B.) \\ 3 Unité des Virus Émergents (UVE: Aix-Marseille Univ, IRD 190, Inserm 1207, IHU Méditerranée Infection), \\ 13000 Marseille, France; cecile.baronti@univ-amu.fr (C.B.); franck.TOURET@univ-amu.fr (F.T.); \\ bruno.coutard@univ-amu.fr (B.C.) \\ 4 Center for AIDS Research, Laboratory of Biochemical Pharmacology, Department of Pediatrics, \\ Emory University School of Medicine and Children's Healthcare of Atlanta, Atlanta, GA 30222, USA; \\ tamara.mcbraye@emory.edu (T.R.M.); rschin@emory.edu (R.F.S.) \\ * Correspondence: vincent.roy@univ-orleans.fr (V.R.); luigi.agrofoglio@univ-orleans.fr (L.A.A.)
}

\section{check for} updates

Citation: Abuduaini, T.; Roy, V.; Marlet, J.; Gaudy-Graffin, C.; Brand, D.; Baronti, C.; Touret, F.; Coutard, B.; McBrayer, T.R.; Schinazi, R.F.; et al. Synthesis and Antiviral Evaluation of (1,4-Disubstituted-1,2,3-Triazol)-(E)-2 Methyl-but-2-Enyl Nucleoside Phosphonate Prodrugs. Molecules 2021, 26, 1493. https://doi.org/ $10.3390 /$ molecules26051493

Academic Editor: Paolo Quadrelli

Received: 16 February 2021

Accepted: 3 March 2021

Published: 9 March 2021

Publisher's Note: MDPI stays neutral with regard to jurisdictional claims in published maps and institutional affiliations.

Copyright: (C) 2021 by the authors. Licensee MDPI, Basel, Switzerland. This article is an open access article distributed under the terms and conditions of the Creative Commons Attribution (CC BY) license (https:/ / creativecommons.org/licenses/by/ $4.0 /)$.
Abstract: A series of hitherto unknown (1,4-disubstituted-1,2,3-triazol)-(E)-2-methyl-but-2-enyl nucleosides phosphonate prodrugs bearing 4-substituted-1,2,3-triazoles were prepared in a straight approach through an olefin acyclic cross metathesis as the key synthetic step. All novel compounds were evaluated for their antiviral activities against HBV, HIV and SARS-CoV-2. Among these molecules, only compound $\mathbf{1 5 j}$, a hexadecyloxypropyl (HDP)/(isopropyloxycarbonyl-oxymethyl)-ester (POC) prodrug, showed activity against HBV in Huh7 cell cultures with $62 \%$ inhibition at $10 \mu \mathrm{M}$, without significant cytotoxicity $\left(\mathrm{IC}_{50}=66.4 \mu \mathrm{M}\right.$ in HepG2 cells, $\mathrm{IC}_{50}=43.1 \mu \mathrm{M}$ in HepG2 cells $)$ at $10 \mu \mathrm{M}$.

Keywords: nucleosides; olefin cross metathesis; ultrasound; copper-catalyzed azide-alkyne cycloaddition (CuAAC); antiviral properties; HBV; HIV; SARS-CoV-2

\section{Introduction}

Acyclic nucleoside phosphonates (ANPs), such as (R)-PMPA [9-[9(R)-2-(phosphonomethoxy)propyl]adenine, 1] and PMEA [9-[2-(phosphonomethoxy)ethyl] adenine, 2] discovered by A. Holý and E. De Clercq in 1986, led to a new family of nucleotide analogs which has attracted considerable attention, [1-4]. In order to improve the oral absorption of these phosphonate analogs, ANPs are delivered as prodrugs [bis(POC)-PMPA (3) or bis(POM)-PMEA (4)]; prodrug moiety [5] has previously focused on acyloxyalkylester (pivaloyloxymethyl, POM) [6,7], or ((isopropyloxycarbonyl-oxymethyl)-ester, POC) [8], alkoxyalkyl groups (hexadecyloxypropyl, HDP) [9], and more recently on phosphonoamidates (ProTides) [10,11]. Currently, several ANP prodrugs (alone or in combination) are FDA-approved drugs against DNA and RNA viruses. In our search for antiviral compounds, we have discovered a new class of acyclic nucleoside phosphonates based on a 4phosphono-but-2-en-1-yl skeleton, with the double bond having trans stereochemistry [12-14]. We have shown that this modification allows for the mimicry of the three-dimensional geometry provided by the backbone of PMEA, PMPA, and CDV ((S)-1-[3-hydroxy-2(phosphonylmethoxy)propyl]cytosine) while maintaining an electronic contribution similar to that brought by the oxygen atom [12]. Our group has published a series of bis(POM)-(1,4disubstituted-1,2,3-triazol)-(E)-but-2'-enyl nucleoside phosphonates [15]. Among them, the 
compound 5 exhibits significant potency against human hepatitis $\mathrm{C}$ virus $(\mathrm{HCV})$ infections at $10 \mu \mathrm{M}$ (95\% of inhibition) meanwhile our synthesized bis(POC)-(E)-2-methyl-but-2enylguanine 6 (unpublished data) showed antiviral activity against hepatitis B virus (HBV) with an $\mathrm{EC}_{50}$ of $8.5 \mu \mathrm{M}$ without significant cytotoxicity (Figure 1).
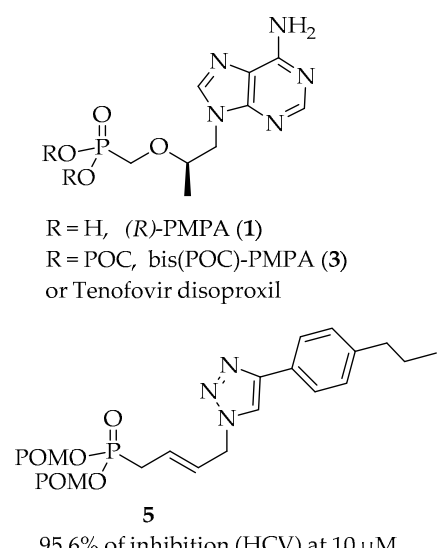

$95.6 \%$ of inhibition (HCV) at $10 \mu \mathrm{M}$ $\mathrm{CC}_{50} 55.3 \mu \mathrm{M}$ (CEM cells)

$\mathrm{POM}=\mathrm{CH}_{2} \mathrm{OC}(\mathrm{O}) t \mathrm{Bu} ; \mathrm{POC}=\mathrm{CH}_{2} \mathrm{OCO}_{2} \mathrm{iPr}$

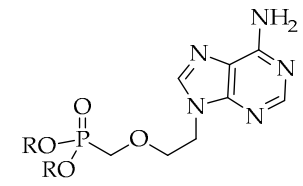

$\mathrm{R}=\mathrm{H}$, PMEA (2)

$\mathrm{R}=\mathrm{POM}$, bis(POM)-PMEA (4)

or Adefovir dipivoxil

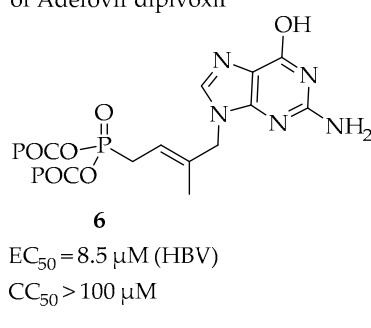

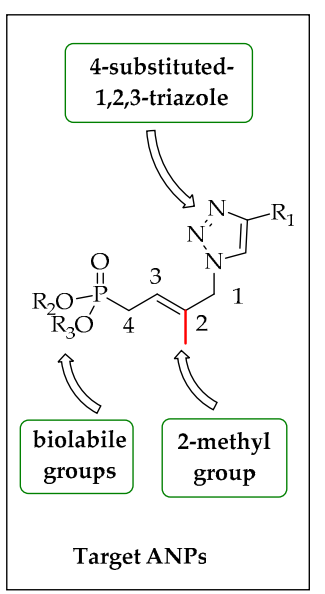

Figure 1. Structure of selected acyclic nucleoside phosphonates (ANPs) and target derivatives. PMPA: 2-(phosphonomethoxy)propyladenine; PMEA: 9-(2-(phosphonomethoxy)ethyl) adenine; POM: pivaloyloxymethyl; POC: (isopropyloxycarbonyl-oxymethyl)-ester.

For nucleosides, it appears that chemical alterations (such as a methyl group at $2^{\prime}$ position) at the sugar (or acyclic side-chain) moiety or at the heterocycle such as 1,2,3triazoles [16] often lead to marked differences in antiviral activity. Based on these findings and on our data for compounds 5 and $\mathbf{6}$, we were interested in the synthesis of hitherto unknown (1,4-disubstituted-1,2,3-triazol)-(E)-2-methyl-but-2-enyl nucleosides phosphonate prodrugs and we wish to compare the impact of bis(POC) with the mixed HDP/POC biolabile moiety on the antiviral activity. All compounds were evaluated against hepatitis $B$ virus (HBV), human immunodeficiency virus (HIV-1) and the newly detected severe acute respiratory syndrome (SARS-CoV-2).

\section{Results and Discussions}

\subsection{Chemistry}

First, we synthetized the bis(POC)allylphosphonate 7 from dimethylallylphosphonate according our previously reported method [14]. Then, optimized olefin cross-metathesis reaction between 7 and 2-methylprop-2-en-1-ol (8) was performed in dry dichloromethane with a Hoveyda-Grubbs catalyst ( $15 \mathrm{~mol} \%$ ) under ultrasonic irradiation at $55^{\circ} \mathrm{C}$ during $24 \mathrm{~h}$ [17], (Scheme 1). The desired compound 9 was obtained in an excellent $94 \%$ yield with only E-isomer; no trace of Z-isomer was detected (NOESY NMR, see Supplementary Materials). Compound 9 was converted to the corresponding mesylate and the obtained sulfone was used directly in the next step without further purification. The introduction of the azido group on the mesylated compound was realized with sodium azide in DMF at room temperature for $5 \mathrm{~h}$ to afford compound $\mathbf{1 0}$ in excellent $93 \%$ yield.<smiles>C=CCP(=O)(O)OC(=O)OCc1ccccc1</smiles>

7

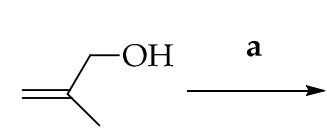

8<smiles>CC(=CCP(=O)(O)OC(=O)O)CO</smiles>

9<smiles>C/C(=C\CP(=O)(O)OC(=O)O)C[NH]</smiles>

10

Scheme 1. Reagents and conditions: (a) Hoveyda-Grubbs catalyst (15 mol\%), dry $\mathrm{CH}_{2} \mathrm{Cl}_{2}, 55{ }^{\circ} \mathrm{C}, 24 \mathrm{~h}, 94 \%$; (b) (i) $\mathrm{MsCl}$, $\mathrm{Et}_{3} \mathrm{~N}$, dry $\mathrm{CH}_{2} \mathrm{Cl}_{2}, 0^{\circ} \mathrm{C}$ to room temperature (rt), $40 \mathrm{~min}$; (ii) $\mathrm{NaN}_{3}, \mathrm{DMF}, \mathrm{rt}, 5 \mathrm{~h}, 93 \%$. 
Compound 10 was engaged in a regioselective copper-catalyzed azide-alkyne 1,3dipolar cycloaddition (CuAAC) $[18,19]$ with seventeen various terminal alkynes (dipolarophiles) selected to bear bulky, polar and apolar groups. The desired 1,4-disubstituted1,2,3-triazoles 11a-q were isolated in good yields ranging from $57 \%$ to $91 \%$ through adequate methods A or B (Table 1). Only compounds $11 \mathrm{~g}$ and $\mathbf{1 1 i}$ were isolated in poor yields. For $11 \mathrm{~m}$, the 2-nitrophenylboronic acid (method B) was added to the solution in order to avoid the decarboxylation of the desired compound [20].

Table 1. Copper-catalyzed azide alkyne cycloaddition to triazolo compounds 11a-q.

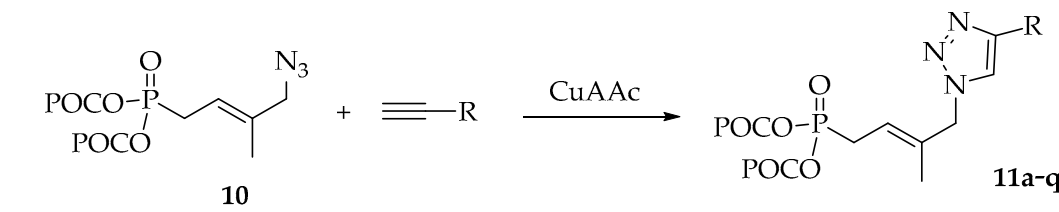

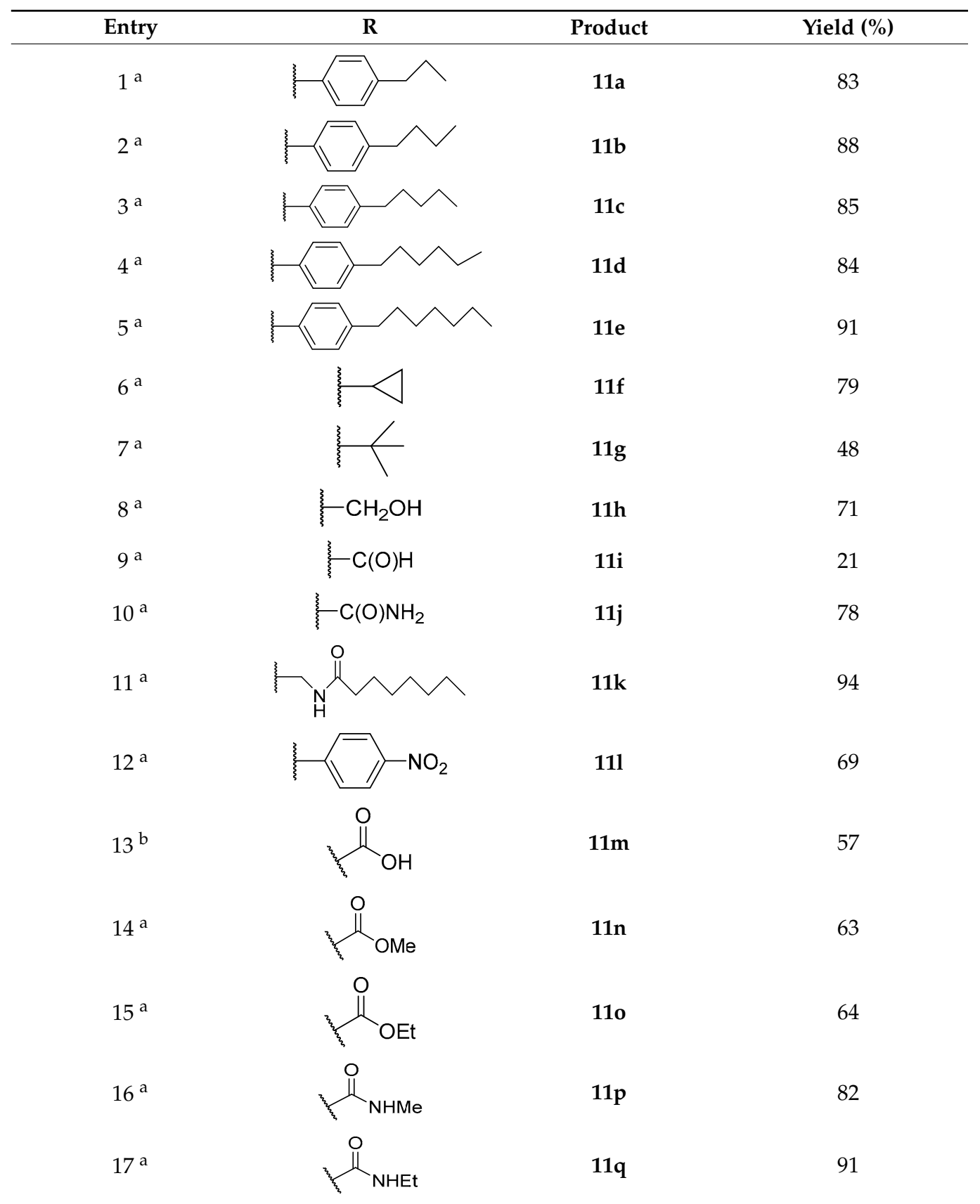

a Method A: $\mathrm{CuSO}_{4} \cdot 5 \mathrm{H}_{2} \mathrm{O}$, sodium ascorbate, $t \mathrm{BuOH} / \mathrm{H}_{2} \mathrm{O}(2: 1), 40{ }^{\circ} \mathrm{C}$, time (followed by thin layer chromatography (TLC)); ${ }^{\mathrm{b}}$ Method B: 2-nitrophenylboronic acid, $\mathrm{CH}_{2} \mathrm{Cl}_{2}, \mathrm{rt}, 42 \mathrm{~h}$. 
From the antiviral evaluation of $\mathbf{1 1 a}-\mathbf{q}$ (see hereafter), it appears that compounds 11a, 11c, 11e, 11j, and 111 have a $>40 \%$ inhibition of $\mathrm{HBV}$, at $10 \mu \mathrm{M}$, with low cytotoxicity. Thus, we focused our attention only to the synthesis of their HDP/POC analogs 15a, 15c, 15e, 15j, 151, (Scheme 2). Starting from HDP/POC allylphosphonate 12, obtained from dimethylallylphosphonate according to our previous method [14], a cross metathesis reaction of $\mathbf{1 2}$ and 2-methyl-2-propen-1-ol (8) in dry dichloromethane using the HoveydaGrubbs catalyst ( $15 \mathrm{~mol} \%$ ) under ultrasonic irradiation at $55{ }^{\circ} \mathrm{C}$ during $24 \mathrm{~h}$ afforded the desired compound $\mathbf{1 3}$ in $88 \%$ yield as only E-isomer.

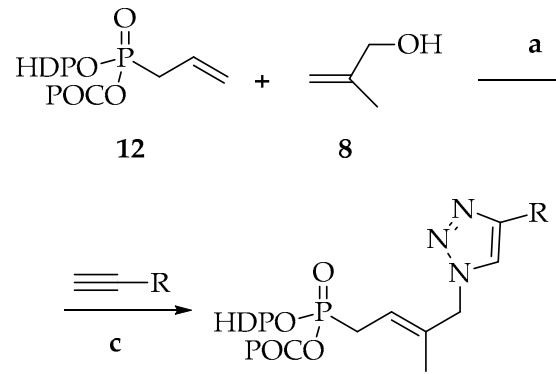

$15 \mathrm{~b}, \mathrm{R}=\mathrm{Ph}\left(\mathrm{p}-\mathrm{C}_{4} \mathrm{H}_{3}\right), 80 \%$ 15c, $\mathrm{R}=\mathrm{Ph}\left(p-\mathrm{C}_{5} \mathrm{H}_{11}\right), 74 \%$<smiles>C/C(=C\CP(=O)([O-])[Po])CO</smiles>

13<smiles>C/C(=C\CP(=O)(Cl)[Po](=O)[O-])C[N]</smiles>

14

Scheme 2. Reagents and conditions: (a) Hoveyda-Grubbs catalyst ( $15 \mathrm{~mol} \%$ ), $\operatorname{dry~} \mathrm{CH}_{2} \mathrm{Cl}_{2}, 55^{\circ} \mathrm{C}, 24 \mathrm{~h}, 88 \%$; (b) (i) $\mathrm{MsCl}$, $\mathrm{Et}_{3} \mathrm{~N}$, dry $\mathrm{CH}_{2} \mathrm{Cl}_{2}, 0^{\circ} \mathrm{C}$ to rt, $40 \mathrm{~min}$; (ii) $\mathrm{NaN}_{3}, \mathrm{DMF}, \mathrm{rt}, 5 \mathrm{~h}, 84 \%$; (c) $\mathrm{CuSO}_{4} .5 \mathrm{H}_{2} \mathrm{O}$, sodium ascorbate, $t \mathrm{BuOH} / \mathrm{H}_{2} \mathrm{O}(2: 1)$, $40{ }^{\circ} \mathrm{C}, 2 \sim 18 \mathrm{~h}, 68 \sim 80 \%$.

Compound 13 was then activated by mesylation from $0{ }^{\circ} \mathrm{C}$ to room temperature (rt) in dry dichloromethane in the presence of methanesulfonyl chloride during $40 \mathrm{~min}$ and the corresponding sulfone was directly engaged in the next step without further purification. Mesylated intermediate was then solubilized in DMF, in the presence of sodium azide at room temperature for $5 \mathrm{~h}$ to afford compound 14 in $84 \%$ yield. The structure of 14 was confirmed by NOESY NMR experiment (Figure 2).
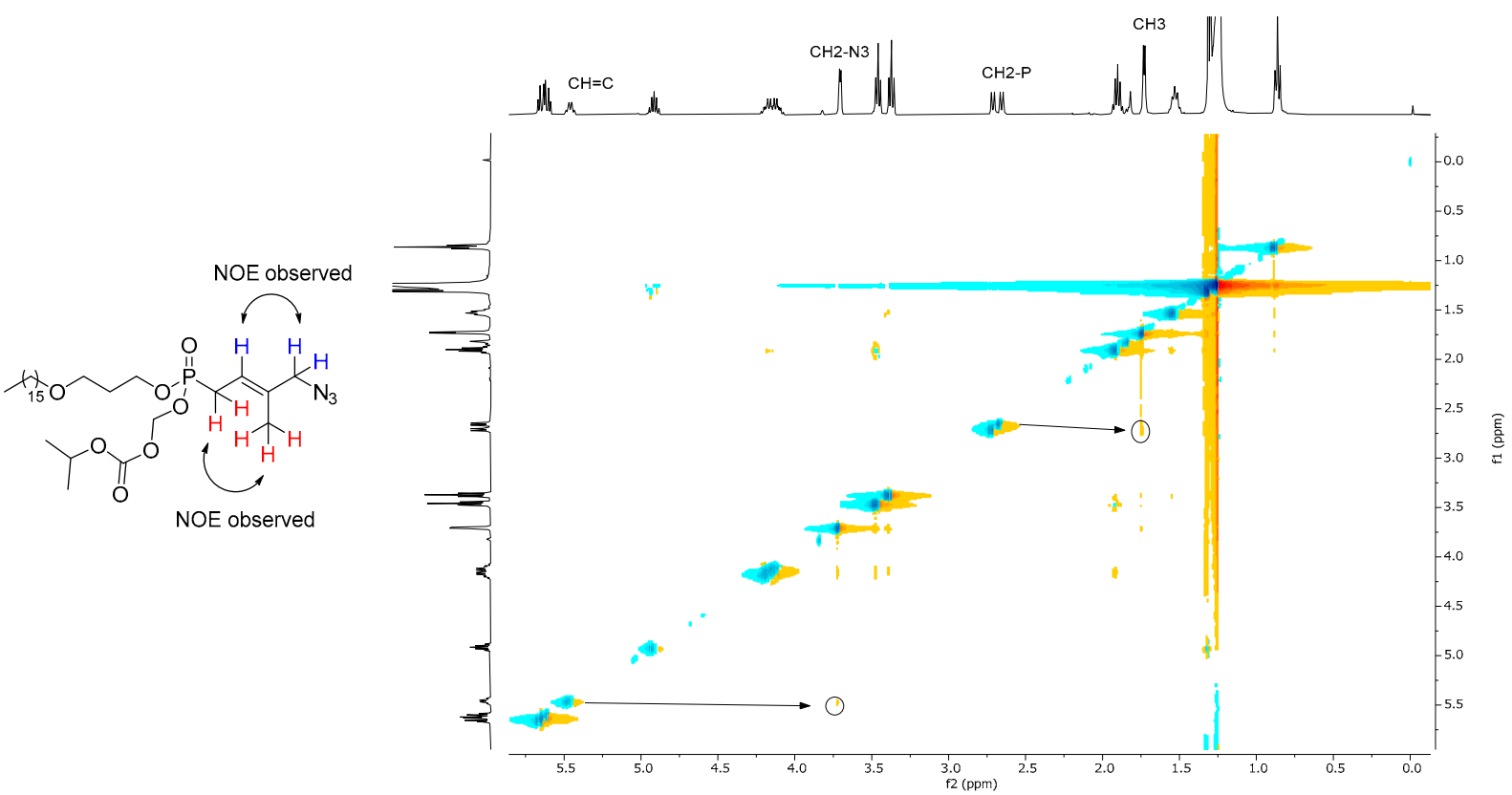

Figure 2. NOESY NMR spectra of 14.

Finally, the CuAAC reaction of $\mathbf{1 4}$ with various substituted phenylacetylenes and non-aromatic terminal alkynes afforded a series of HDP/POC-(1,4-disubstituted-1,2,3triazol)-2'-methyl-but-2'-enylphosphonate 15a, 15c, 15e, 15j, 15l, respectively, in good yields ranging from $68 \%$ to $80 \%$. 


\subsection{Antiviral Evaluation}

All synthesized compounds, the (1,4-disubstituted-1,2,3-triazol)-(E)-2-methyl-but-2enyl nucleosides phosphonate prodrugs 11a-q, 15a, 15c, 15e, 15j, 15l, were tested for their antiviral activities in vitro against HIV, HBV and SARS-CoV-2 viruses; the results are summarized in Table 2 and represent means from triplicate wells.

Table 2. Antiviral activity and cytotoxicity of synthesized compounds in cellular assays at $10 \mu \mathrm{M}$.

\begin{tabular}{|c|c|c|c|c|c|c|c|}
\hline \multirow[b]{4}{*}{ Cmpd } & \multirow{2}{*}{\multicolumn{3}{|c|}{$11 a-q$}} & \multicolumn{3}{|c|}{$15 a-c, e, j, 1$} & \\
\hline & & & & SARS-CoV-2 & HIV & & \\
\hline & \multicolumn{2}{|c|}{$\%$ Inhibition } & \multirow{2}{*}{$\begin{array}{c}\text { \% Cell Viability } \\
\text { Huh7 }\end{array}$} & \multirow{2}{*}{$\begin{array}{c}\text { \% Inhibition } \\
\text { Vero E6 }\end{array}$} & \multirow{2}{*}{$\begin{array}{c}\text { \% Inhibition } \\
\text { PBM }\end{array}$} & \multicolumn{2}{|c|}{$\begin{array}{l}\text { Cytotoxicity } \\
\left(\mathrm{IC}_{50}, \mu \mathrm{M}\right)\end{array}$} \\
\hline & Huh7 & HepAD38 & & & & PBM & HepG2 \\
\hline 11a & 51 & 19.6 & 96 & $<1$ & $<1$ & 50.2 & 18.3 \\
\hline $11 b$ & 25 & 14.4 & 88 & $<1$ & $<1$ & 19.4 & 16.2 \\
\hline 11c & 42 & $<1$ & 89 & $<1$ & 44.4 & 47.8 & 51.8 \\
\hline $11 d$ & 39 & 38.8 & 100 & $<1$ & 41.8 & 23.7 & 59.6 \\
\hline $11 \mathrm{e}$ & 50 & 33.5 & 95 & $<1$ & 29.9 & 9.2 & 90.8 \\
\hline $11 f$ & $<1$ & 36.3 & 100 & $<1$ & 30.7 & 25.5 & $>100$ \\
\hline $11 \mathrm{~g}$ & 10 & 17.3 & 79 & $<1$ & 12.3 & 28.3 & $>100$ \\
\hline $11 \mathrm{~h}$ & 28 & 15.1 & 100 & 12 & $<1$ & 76.4 & $>100$ \\
\hline $11 \mathrm{i}$ & 33 & 6.1 & 95 & $<1$ & 28.4 & 75.1 & $>100$ \\
\hline $\mathbf{1 1 j}$ & 40 & 31.3 & 100 & $<1$ & $<1$ & 76.8 & $>100$ \\
\hline $11 k$ & $<1$ & 6.1 & 100 & 5 & 42 & 51.5 & 57.3 \\
\hline 111 & 40 & 42.6 & 100 & 10 & 38.8 & 23.5 & 85.3 \\
\hline $11 \mathrm{~m}$ & 12 & 41.3 & 57 & $<1$ & 12.9 & $>100$ & $>100$ \\
\hline $11 n$ & 28 & 3.9 & 60 & $<1$ & $<1$ & 40.9 & $>100$ \\
\hline 110 & $<1$ & 41.2 & 60 & $<1$ & 22.4 & 67.5 & $>100$ \\
\hline $11 p$ & 14 & $<1$ & 54 & $<1$ & 36.4 & 78.3 & $>100$ \\
\hline $11 q$ & $<1$ & $<1$ & 90 & $<1$ & 31.2 & 80.6 & $>100$ \\
\hline $15 a$ & $<1$ & ND & 95 & $<1$ & ND & ND & ND \\
\hline $15 c$ & 14 & 28.8 & 47 & $<1$ & 28.2 & 50.5 & $>100$ \\
\hline $15 e$ & 8 & ND & 100 & $<1$ & ND & ND & ND \\
\hline $15 j$ & 62 & $<1$ & 74 & $<1$ & 32.2 & 43.1 & 66.4 \\
\hline 151 & 12 & ND & 100 & $<1$ & ND & ND & ND \\
\hline Entecavir & 92 & - & 96 & - & - & - & - \\
\hline Remdesivir & - & - & - & 100 & - & - & - \\
\hline
\end{tabular}

ND, not determined; PBM, peripheral blood mononuclear; cmpd, compound.

None of the compounds tested displayed anti-HIV activity compared to positive control AZT ( $\mathrm{EC}_{50}$ of $0.008 \mu \mathrm{M}$ (data not shown). None of the compounds displayed antiSARS-CoV-2 activity compared to positive control remdesivir. Compounds 11a,c-e, 11j and 111 were found to exhibit a moderate anti-HBV activity compared to entecavir (on Huh7 cells) and lamivudine (on HepAd38).

It is worth noting that the substituent on triazole ring has a dramatic effect on HBV activity. In fact, compounds with hydrophobic aryl groups (electron-donating 11a-e and electron-withdrawing 111) exhibited good activity (except for 11b), whereas triazolyl-ANPs with alkyl (11f,g) or polar substituents such as alcohol (11h), aldehyde (11i), formamide (11j) and amide (11k) and carboxylic derivatives $(\mathbf{1 1} \mathbf{m}-\mathbf{q})$ have only low activity. We can speculate that the hydrophobic pocket (formed by A87, F88, P177, L180, and M2) found in the rear of the RT dNTP binding site of HBV could interact with hydrophobic aryl residues through donor atom- $\pi$ interaction [21]. 
Compound 15j, a HDP/POC prodrug, a ribavirin analog, is the most active drug against $\mathrm{HBV}$ in this serial, with $62 \%$ inhibition at $10 \mu \mathrm{M}$. However, generally speaking, the bis(POC) ester prodrugs are more active than their HDP/POC counterparts. The cytotoxicity of test compounds was performed in different cell systems. Positive control cycloheximide exhibited expected toxicity in the peripheral blood mononuclear (PBM) and HepG2 cells, with an $\mathrm{IC}_{50}(\mu \mathrm{M})$ of 1.0 and $1.5 \mu \mathrm{M}$, respectively (data not shown).

\section{Materials and Methods}

\subsection{Chemistry General Section}

Commercially available chemicals were provided as reagent grade and used as received. Some reactions requiring anhydrous conditions were carried out using oven-dried glassware and under an atmosphere of dry argon. All anhydrous solvents were provided from commercial sources as very dry reagents. The reactions were monitored by thin layer chromatography (TLC) analysis using silica gel precoated plates (Kieselgel 60F254, E. Merck). Compounds were visualized by UV irradiation and/or spraying with sulfuric acid $\left(\mathrm{H}_{2} \mathrm{SO}_{4} 5 \%\right.$ in ethanol) stain followed by charring at average $150{ }^{\circ} \mathrm{C}$. Flash column chromatography was performed on silica gel $60 \mathrm{M}(0.040-0.063 \mathrm{~mm}$, E. Merck). The infrared spectra were measured with the Perkin-Elmer Spectrometer. The ${ }^{1} \mathrm{H}$ and ${ }^{13} \mathrm{C}$ NMR spectra were recorded on the BrukerAvance DPX 250 or BrukerAvance 400 Spectrometer (Bruker, Champs sur Marne, France). Chemical shifts are given in ppm and are referenced to the deuterated solvent signal or to TMS as internal standard and multiplicities are reported as $\mathrm{s}$ (singlet), $\mathrm{d}$ (doublet), $\mathrm{t}$ (triplet), $\mathrm{q}$ (quartet) and $\mathrm{m}$ (multiplet). Carbon multiplicities were assigned by distortionless enhancement by polarization transfer (DEPT) experiments. ${ }^{1} \mathrm{H}$ and ${ }^{13} \mathrm{C}$ signals were attributed on the basis of $\mathrm{H}-\mathrm{H}$ and $\mathrm{H}-\mathrm{C}$ correlations. High resolution mass spectra were performed on a Bruker Q-TOF MaXis spectrometer (Bruker Daltonics, Bremen, Germany) by the "Fédération de Recherche" ICOA/CBM (FR2708) platform. LC-MS data were acquired on a Thermo-Fisher UHPLC-MSQ system equipped with an electron spray ionization source (ESI). The temperature of the source was maintained at $350^{\circ} \mathrm{C}$. Initially, the cone voltage was set at $35 \mathrm{~V}$ and after $5 \mathrm{~min}$ was increased to $75 \mathrm{~V}$. In full scan mode, data were acquired between 100 and $1000 \mathrm{~m} / z$ in the positive mode with a $1.00 \mathrm{~s}$ scan time. In addition, a UV detection was performed with a diode array detector at three wavelengths 273,254 and $290 \mathrm{~nm}$, respectively. A water/methanol $(70 \% / 30 \%)$ solution mixture with $0.1 \%$ formic acid was used as the mobile phase. The composition of the mobile phase was increased to $100 \%$ methanol with $0.1 \%$ formic acid with a $7 \%$ ramp. The flow rate was set at $0.300 \mathrm{~mL} \mathrm{~min}^{-1}$. Samples diluted in the mobile phase were injected $(3 \mu \mathrm{L})$ on a C18 column (X-terra, Waters), with a $2.1 \mathrm{~mm}$ internal diameter, and $100 \mathrm{~mm}$ length, and placed into an oven at $40{ }^{\circ} \mathrm{C}$. The electronic extraction of ions was performed and the subsequent areas under the corresponding chromatographic peaks determined. The compounds' name follows the IUPAC recommendations.

\subsection{Antiviral Evaluation}

\subsubsection{HBV Assay}

In Huh7 cells: antiviral activity against HBV in cell culture was measured as previously described [22]. Briefly, Huh7 cells were transfected with plasmid pCI_HBVpg1820 containing 1.1 unit of HBV genome under the control of a human cytomegalovirus (CMV) promoter. The drugs were stored at $1000 \times$ in DMSO at $-20^{\circ} \mathrm{C}$. For each experiment, the drugs were diluted in DMEM cell culture medium (Thermo Fisher Scientific, Artenay, France) to a final concentration of $10 \mu \mathrm{M}$. All drugs were tested in triplicate in two independent experiments. After 4 days of culture, intracapsid viral DNA was quantified by duplex real-time PCR, using primers described elsewhere, on a LightCycler 480 II apparatus (Roche Diagnostics France, Meylan, France) using TaqMan Universal PCR Mastermix II without UNG (Thermo Fisher Scientific, Artenay, France). Cells were quantified using primers by real-time PCR, using primers HPRT1_F (5'-TGCAGACTTTGCTTTCCTTGGTC) and HPRT1_R (5'-CAAGCTTGCGACCTTGACCATC), on a LightCycler 480 II apparatus 
(Roche) using a LightCycler ${ }^{\circledR} 480$ SYBR Green I Master (Roche Diagnostics France, Meylan, France). Cycling reactions were performed with the following parameters: $5 \mathrm{~min}$ at $95^{\circ} \mathrm{C}$, followed by 45 cycles of $10 \mathrm{~s}$ at $95{ }^{\circ} \mathrm{C}, 15 \mathrm{~s}$ at $60^{\circ} \mathrm{C}, 10 \mathrm{~s}$ at $72{ }^{\circ} \mathrm{C}$. The inhibition of HBV replication (\%) and cell culture viability (\%) were quantified using the following formulas.

$$
\begin{gathered}
\text { Inhibition of } H B V \text { replication }(\%)=1-\frac{\text { HBV DNA copy number }}{\text { Drug }} \\
\text { Cell viability }(\%)=\frac{\text { HPRT1 DNA copy number }}{\text { Drug }}{ }_{\text {HPRT1 DNA copy number }} \text { Cell culture medium }_{\text {Hedium }}
\end{gathered}
$$

In HepAD38 cells [23] were seeded at 50,000 cells/well in collagen-coated 96-well plates. Test compounds or $2^{\prime}, 3^{\prime}$-didéoxy-3'-thiacytidin (3TC) (control) were added to HepAD38 cells to a final concentration of $10 \mu \mathrm{M}$.

Real-Time PCR for HBV DNA. The experiment lasted 7 days. On day 7, total DNA was purified from the supernatant using a commercially available kit (DNeasy 96 Blood \& Tissue kit, Qiagen). The HBV DNA was amplified in a real-time PCR assay using a LightCycler 480 (Roche) as described elsewhere [24]. All samples were tested in duplicate in two to three independent experiments. Analysis: The concentration of compound that inhibited HBV DNA replication by $50 \%\left(\mathrm{EC}_{50}\right)$ was determined by linear regression.

\subsubsection{HIV Assay}

The assay was performed as described by Schinazi et al. $[25,26]$ with minor modifications [26]. Briefly, human PBM cells were stimulated with PHA/IL-2 prior to infection with HIV-1 LAI (MOI 0.1) for 5 days in the presence of test compounds with a final concentration of $10 \mu \mathrm{M}$ (LA-338-366) or AZT (control). The supernatants were harvested, and the HIV-1 RT was quantified. The median effective concentrations $\left(\mathrm{EC}_{50 / 90}\right)$ were determined using the method of Belen'kii and Schinazi [27].

\subsubsection{SARS-CoV-2 Assay}

Vero E6 (ATCC CRL-1586) cells were grown in a minimal essential medium (MEM) (Life Technologies, Carlsbad, CA, USA) with 7.5\% heat-inactivated fetal calf serum (FCS), at $37{ }^{\circ} \mathrm{C}$ with $5 \% \mathrm{CO}_{2}$ with $1 \%$ penicillin/streptomycin (PS, $5000 \mathrm{U}^{\mathrm{mL}}{ }^{-1}$ and $5000 \mu \mathrm{g} \cdot \mathrm{mL}^{-1}$, respectively; Life Technologies) and supplemented with 1\% non-essential amino acids (Life Technologies). SARS-CoV-2 strain BavPat1 was obtained from Pr Drosten through EVA GLOBAL (https: / / www.european-virus-archive.com, accessed on 23 February 2021). To prepare the virus working stock, a $25 \mathrm{~cm}^{2}$ culture flask of confluent Vero E6 cells growing with MEM medium with 2.5\% FBS (Life Technologies) was inoculated at MOI 0.001. The cell supernatant medium was harvested at the peak of infection and supplemented with $25 \mathrm{mM}$ HEPES (Sigma, St. Louis, MO, USA) before being stored frozen in small aliquots at $-80^{\circ} \mathrm{C}$. All experiments were conducted in a BSL3 laboratory. One day prior to infection, for the antiviral screening $5 \times 10^{4}$ Vero E6 cells were seeded in 100 of $\mu \mathrm{L}$ the assay medium (containing $2.5 \%$ FCS) in 96 well plates. The next day, four 2 -fold serial dilutions of compounds ( $20 \mu \mathrm{M}$ to $2.5 \mu \mathrm{M}$, in duplicate) were added to the cells $(25 \mu \mathrm{L} /$ well, in the assay medium) as well as two internal well controls of viral inhibition corresponding to the addition of $10 \mu \mathrm{M}$ of Remdesivir (BLDpharm, Hyderabad, India). Three virus control wells were supplemented with $25 \mu \mathrm{L}$ of assay medium (positive controls hereafter named vc) and three cell control wells were supplemented with $50 \mu \mathrm{L}$ of the medium (negative controls, hereafter named nc). After $15 \mathrm{~min}, 25 \mu \mathrm{L}$ of a virus mix diluted in $2.5 \%$ FCS-containing medium was added to the wells at MOI 0.002. Three days after infection, the cell supernatant media was discarded and CellTiter-Blue ${ }^{\circledR}$ reagent (Promega, Madison, WI, USA) was added following the manufacturer's instructions. Plates were incubated for $2 \mathrm{~h}$ prior to recording the fluorescence $(560 / 590 \mathrm{~nm})$ with a Tecan Infinite 200Pro machine. From the measured $\mathrm{OD}_{590 \mathrm{~nm}}$, the inhibition percentage was calculated as follows: $\left(\left(\mathrm{OD}_{590 \mathrm{~nm}}\right.\right.$ value- mean $\mathrm{OD}_{590 \mathrm{~nm}}$ value of $\left.\mathrm{vc}\right) /\left(\right.$ mean $\mathrm{OD}_{590 \mathrm{~nm}}$ of nc- mean 
$\mathrm{OD}_{590 \mathrm{~nm}}$ value of $\left.\left.\mathrm{vc}\right)\right)^{*}$ 100. All data obtained were analyzed using GraphPad Prism 7 software (Graph pad software).

\subsubsection{Cytotoxicity Assays}

Assays were performed in human peripheral blood mononuclear (PBM) and human liver (HepG2) cells via MTS assay using the CellTiter $96^{\circledR}$ Non-Radioactive Cell Proliferation (Promega) kit as previously described ${ }^{3}$. Cytotoxicity was expressed as the concentration of test compounds that inhibited cell proliferation by $50 \%\left(\mathrm{IC}_{50}\right)$ and calculated using the Chou and Talalay method [28].

\subsection{Experimental Section}

(E)-4-Hydroxy-3-methyl-but-2-enyl-bis(POC)phosphonate (9)

To a solution of bis(POC) allylphosphonate (7) (500 mg, 2.0 eq., $1.41 \mathrm{mmol})$ and 2methyl-2-propen-1-ol (8) $(59 \mu \mathrm{L}, 1.0$ eq., $0.71 \mathrm{mmol})$ in dry $\mathrm{CH}_{2} \mathrm{Cl}_{2}(5 \mathrm{~mL})$, Hoveyda-Grubbs catalyst $(66 \mathrm{mg}, 15 \mathrm{~mol} \%, 0.11 \mathrm{mmol})$ was added. The catalyst addition was performed in five equal portions of $3 \mathrm{~mol} \%(13.20 \mathrm{mg}, 0.021 \mathrm{mmol})$ at $\mathrm{t}=0,3,6,9$ and $21 \mathrm{~h}$ over the course of the reaction. The solution was sonicated at $55{ }^{\circ} \mathrm{C}$ under nitrogen atmosphere for $24 \mathrm{~h}$. Volatiles were evaporated and the residue was purified by silica gel column chromatography (EtOAc/PE, 7:3) to give the desired phosphonate derivative 9 (264 mg, 94\%) as brown oil. ${ }^{1} \mathrm{H}$ NMR $\left(400 \mathrm{MHz}, \mathrm{CDCl}_{3}\right) \delta 5.65-5.57\left(\mathrm{~m}, 4 \mathrm{H}, \mathrm{O}-\mathrm{CH}_{2}-\mathrm{O}\right), 5.41-5.37$ $(\mathrm{m}, 1 \mathrm{H}, \mathrm{CH}=\mathrm{C}), 4.87$ (sept., $\left.J=6.2 \mathrm{~Hz}, 2 \mathrm{H}, \mathrm{CH}\left(\mathrm{CH}_{3}\right)_{2}\right), 3.98\left(\mathrm{~d}, J=5.3 \mathrm{~Hz}, 2 \mathrm{H}, \mathrm{CH}_{2}-\mathrm{OH}\right)$, $2.69\left(\mathrm{dd}, J=22.7,7.6 \mathrm{~Hz}, 2 \mathrm{H}, \mathrm{CH}_{2}-\mathrm{P}\right), 2.34(\mathrm{~s}, 1 \mathrm{H}, \mathrm{OH}), 1.65\left(\mathrm{~d}, J=4.5 \mathrm{~Hz}, 3 \mathrm{H}, \mathrm{CH}_{3}\right), 1.28$ $\left(\mathrm{d}, \mathrm{J}=6.3 \mathrm{~Hz}, 12 \mathrm{H}, \mathrm{CH}\left(\mathrm{CH}_{3}\right)_{2}\right) .{ }^{13} \mathrm{C} \mathrm{NMR}\left(101 \mathrm{MHz}, \mathrm{CDCl}_{3}\right) \delta 153.2(\mathrm{C}=\mathrm{O}), 141.6,141.5$ $(\mathrm{CH}=\mathrm{C}), 111.6,111.5(\mathrm{CH}=\mathrm{C}), 84.1,84.1\left(\mathrm{O}-\mathrm{CH}_{2}-\mathrm{O}\right), 73.3\left(\mathrm{CH}\left(\mathrm{CH}_{3}\right)_{2}\right), 68.0,68.0\left(\mathrm{CH}_{2}-\mathrm{OH}\right)$, 27.3, $25.9\left(\mathrm{CH}_{2}-\mathrm{P}\right), 21.6\left(\mathrm{CH}\left(\mathrm{CH}_{3}\right)_{2}\right), 13.9,13.9\left(\mathrm{CH}_{3}\right) .{ }^{31} \mathrm{P} \mathrm{NMR}\left(162 \mathrm{MHz}, \mathrm{CDCl}_{3}\right) \delta 28.80$. HRMS (ESI): $m / z[\mathrm{M}+\mathrm{H}]^{+}$calcd for $\mathrm{C}_{15} \mathrm{H}_{28} \mathrm{O}_{10} \mathrm{P}: 399.14146$, found: 399.14151 .

(E)-4-Azido-3-methyl-but-2-enyl-bis(POC)phosphonate (10)

To a solution of (E)-4-hydroxy-3-methyl-but-2-enyl-bis(POC)phosphonate 9 (264 mg, 1.0 equiv., $0.66 \mathrm{mmol})$ in anhydrous $\mathrm{CH}_{2} \mathrm{Cl}_{2}(5 \mathrm{~mL})$ were added dropwise methanesulfonyl chloride $(56 \mu \mathrm{L}, 1.1$ equiv., $0.73 \mathrm{mmol})$ and anhydrous triethylamine (102 $\mu \mathrm{L}, 1.1$ equiv., $0.73 \mathrm{mmol}$ ) at $0{ }^{\circ} \mathrm{C}$ under the argon. After $30 \mathrm{~min}$ stirring at room temperature, the mixture was diluted with $\mathrm{CH}_{2} \mathrm{Cl}_{2}$ and washed with brine solution $(3 \times 10 \mathrm{~mL})$. The organic layers were dried over $\mathrm{MgSO}_{4}$, filtrated and concentrated in vacuo. The residue was directly used for the next step without further purification. Thus, it was dissolved in anhydrous DMF ( $8 \mathrm{~mL})$ and sodium azide (216 $\mathrm{mg}, 5.0$ equiv., $3.32 \mathrm{mmol}$ ) was added under nitrogen atmosphere. After $5 \mathrm{~h}$ stirring at room temperature, the mixture was diluted with EtOAc, washed with water and then extracted with EtOAc. The combined organic layers were washed with brine solution $(5 \times 10 \mathrm{~mL})$, dried over $\mathrm{MgSO}_{4}$, and concentrated in vacuo. The residue was purified by silica gel column chromatography (EtOAc/PE, 4:6) to give 10 (261 mg, 93\%) as a colorless oil. ${ }^{1} \mathrm{H}$ NMR $\left(400 \mathrm{MHz}, \mathrm{CDCl}_{3}\right) \delta 5.71-5.61\left(\mathrm{~m}, 4 \mathrm{H}, \mathrm{O}-\mathrm{CH}_{2}-\mathrm{O}\right)$, 5.48-5.42 (m, 1H, CH=C), 4.92 (sept, $\left.J=6.2 \mathrm{~Hz}, 2 \mathrm{H}, \mathrm{CH}\left(\mathrm{CH}_{3}\right)_{2}\right), 3.71(\mathrm{~d}, J=4.0 \mathrm{~Hz}, 2 \mathrm{H}$, $\left.\mathrm{CH}_{2}-\mathrm{N}_{3}\right), 2.75\left(\mathrm{dd}, J=23.1,7.9, \mathrm{~Hz}, 2 \mathrm{H}, \mathrm{CH}_{2}-\mathrm{P}\right), 1.73\left(\mathrm{~d}, J=4.5 \mathrm{~Hz}, 3 \mathrm{H}, \mathrm{CH}_{3}\right), 1.32(\mathrm{~d}$, $\left.J=6.2 \mathrm{~Hz}, 12 \mathrm{H}, \mathrm{CH}\left(\mathrm{CH}_{3}\right)_{2}\right) .{ }^{13} \mathrm{C} \mathrm{NMR}\left(101 \mathrm{MHz}, \mathrm{CDCl}_{3}\right) \delta 153.2(\mathrm{C}=\mathrm{O}), 136.2,136.1$ $(\mathrm{C}=\mathrm{CH}), 116.4,116.3(\mathrm{CH}=\mathrm{C}), 84.2,84.1\left(\mathrm{O}-\mathrm{CH}_{2}-\mathrm{O}\right), 73.3\left(\mathrm{CH}\left(\mathrm{CH}_{3}\right)_{2}\right)$, 58.6, $58.6\left(\mathrm{CH}_{2}-\mathrm{N}_{3}\right)$, $27.6\left(\mathrm{CH}_{2}-\mathrm{P}\right), 26.2\left(\mathrm{CH}_{2}-\mathrm{P}\right), 21.6\left(\mathrm{CH}\left(\mathrm{CH}_{3}\right)_{2}\right), 14.9,14.9\left(\mathrm{CH}_{3}\right) .{ }^{31} \mathrm{P} \mathrm{NMR}\left(162 \mathrm{MHz}, \mathrm{CDCl}_{3}\right)$ $\delta$ 27.85. IR $v_{\max } 2985.61,2937.37,2100.12,1755.01,1255.06,1031.52,984.34,949.97,904.26$, 832.67, $788.47 \mathrm{~cm}^{-1}$. HRMS (ESI): $m / z$ [M+Na] ${ }^{+}$calcd for $\mathrm{C}_{15} \mathrm{H}_{26} \mathrm{~N}_{3} \mathrm{NaO}_{9} \mathrm{P}: 446.12988$, found: 446.12990 .

General procedures A for CuAAC reaction

To a solution of (E)-4-Azido-3-methyl-but-2-enyl-bis(POC)phosphonate 10 (1.0 equiv.) and alkyne (1.3 equiv.) in $t \mathrm{BuOH} / \mathrm{H}_{2} \mathrm{O}(2: 1)$ were added sodium ascorbate (0.6 equiv.) and $\mathrm{CuSO}_{4} .5 \mathrm{H}_{2} \mathrm{O}$ (0.1 equiv.). The resulting suspension was stirred at $40{ }^{\circ} \mathrm{C}$ until completion (followed by TLC), then the crude mixture was co-evaporated five times with methanol 
(10 mL). The residue was purified by silica gel column chromatography using elution gradient of petroleum ether/ethyl acetate to give the desired bis(POC) phosphonate derivatives. [[(E)-4-[4-(4-Propylphenyl)triazol-1-yl]-3-methyl-but-2-enyl]-(isopropoxycarbonyloxymethoxy)phosphoryl]oxymethyl isopropyl carbonate (11a)

The title compound was prepared from 10 (101 mg, $0.24 \mathrm{mmol})$ and 1-ethynyl-4propylbenzene $(49 \mu \mathrm{L} \mathrm{mg}, 0.31 \mathrm{mmol})$ following the general procedure $\mathrm{A}$; the resulting suspension was stirred for $2 \mathrm{~h}$ at $40^{\circ} \mathrm{C}$. After purification on a silica gel column chromatography (EtOAc/PE, 4:6), the desired pure compound 11a $(112 \mathrm{mg}, 83 \%)$ was obtained as a colorless oil. ${ }^{1} \mathrm{H} \mathrm{NMR}\left(250 \mathrm{MHz}, \mathrm{CDCl}_{3}\right) \delta 7.76\left(\mathrm{~s}, 1 \mathrm{H}, \mathrm{H}^{5}\right), 7.74\left(\mathrm{~d}, J=5.7 \mathrm{~Hz}, 2 \mathrm{H}, \mathrm{H}^{\mathrm{Ar}}\right)$, 7.25-7.17 (d, $\left.J=8.5 \mathrm{~Hz}, 2 \mathrm{H}, \mathrm{H}^{\mathrm{Ar}}\right), 5.77-5.51\left(\mathrm{~m}, 4 \mathrm{H}, \mathrm{O}-\mathrm{CH}_{2}-\mathrm{O} ; 1 \mathrm{H}, \mathrm{CH}=\mathrm{C}\right), 4.98-4.80$ (m, $\left.2 \mathrm{H}, \mathrm{CH}_{2}-\mathrm{N} ; 2 \mathrm{H}, \mathrm{CH}\left(\mathrm{CH}_{3}\right)_{2}\right), 2.78\left(\mathrm{dd}, \mathrm{J}=23.1,7.8 \mathrm{~Hz}, 2 \mathrm{H}, \mathrm{CH}_{2}-\mathrm{P}\right), 2.59(\mathrm{t}, J=7.6 \mathrm{~Hz}, 2 \mathrm{H}$, $\left.\mathrm{Ar}-\mathrm{CH}_{2}\right), 1.70-1.58\left(\mathrm{~m}, 3 \mathrm{H}, \mathrm{CH}_{3} ; 2 \mathrm{H}, \mathrm{Ar}-\mathrm{CH}_{2}-\mathrm{CH}_{2}\right), 1.27\left(\mathrm{~d}, \mathrm{~J}=6.3 \mathrm{~Hz}, 12 \mathrm{H}, \mathrm{CH}\left(\mathrm{CH}_{3}\right)_{2}\right)$, $0.93\left(\mathrm{t}, J=7.3 \mathrm{~Hz}, 3 \mathrm{H}, \mathrm{Ar}-\mathrm{CH}_{2}-\mathrm{CH}_{2}-\mathrm{CH}_{3}\right) .{ }^{13} \mathrm{C} \mathrm{NMR}\left(101 \mathrm{MHz}, \mathrm{CDCl}_{3}\right) \delta 153.2(\mathrm{C}=\mathrm{O}), 148.3$ $\left(\mathrm{C}^{\mathrm{q}, \mathrm{Ar}}\right), 142.7\left(\mathrm{C}^{\mathrm{q}}, \mathrm{Ar}\right), 135.9,135.7(\mathrm{CH}=\mathrm{C}), 128.9\left(\mathrm{CH}^{\mathrm{Ar}}\right), 128.1\left(\mathrm{C}^{\mathrm{q}}, \mathrm{Ar}\right), 125.6\left(\mathrm{CH}^{\mathrm{Ar}}\right), 119.0$ $\left(\mathrm{CH}^{\mathrm{Ar}}\right), 118.1,118.0(\mathrm{CH}=\mathrm{C}), 84.1,84.1\left(\mathrm{O}-\mathrm{CH}_{2}-\mathrm{O}\right), 73.4\left(\mathrm{CH}\left(\mathrm{CH}_{3}\right)_{2}\right), 57.8,57.8\left(\mathrm{CH}_{2}-\mathrm{N}\right)$, $37.8\left(\mathrm{Ar}_{-} \mathrm{CH}_{2}\right), 27.8,26.4\left(\mathrm{CH}_{2}-\mathrm{P}\right), 24.5\left(\mathrm{Ar}-\mathrm{CH}_{2}-\mathrm{CH}_{2}\right), 21.6,21.6\left(\mathrm{CH}\left(\mathrm{CH}_{3}\right)_{2}\right), 14.2,14.2$ $\left(\mathrm{CH}_{3}\right), 13.8\left(\mathrm{Ar}-\mathrm{CH}_{2}-\mathrm{CH}_{2}-\mathrm{CH}_{3}\right) .{ }^{31} \mathrm{P} \mathrm{NMR}\left(162 \mathrm{MHz}, \mathrm{CDCl}_{3}\right) \delta 27.47$. HRMS (ESI): $\mathrm{m} / z$ $[\mathrm{M}+\mathrm{H}]^{+}$calcd for $\mathrm{C}_{26} \mathrm{H}_{39} \mathrm{~N}_{3} \mathrm{O}_{9} \mathrm{P}: 568.24184$, found: 568.24217.

[[(E)-4-[4-(4-Butylphenyl)triazol-1-yl]-3-methyl-but-2-enyl]-(isopropoxycarbonyloxymethoxy)phosphoryl]oxymethyl isopropyl carbonate (11b)

The title compound was prepared from 10 (102 mg, $0.24 \mathrm{mmol})$ and 1-butyl-4-ethynylbenzene $(55 \mu \mathrm{L}, 0.31 \mathrm{mmol})$ following the general procedure $\mathrm{A}$; the resulting suspension was stirred for $2 \mathrm{~h}$ at $40{ }^{\circ} \mathrm{C}$. After purification on a silica gel column chromatography (EtOAc/PE, 4:6), the desired pure compound $\mathbf{1 1 b}(123 \mathrm{mg}, 88 \%)$ was obtained as a colorless oil. ${ }^{1} \mathrm{H} \mathrm{NMR}\left(250 \mathrm{MHz}, \mathrm{CDCl}_{3}\right) \delta 7.76\left(\mathrm{~d}, J=7.8 \mathrm{~Hz}, 2 \mathrm{H}, \mathrm{H}^{\mathrm{Ar}}\right), 7.75\left(\mathrm{~s}, 1 \mathrm{H}, \mathrm{H}^{5}\right), 7.22$ $\left(\mathrm{d}, \mathrm{J}=7.8 \mathrm{~Hz}, 2 \mathrm{H}, \mathrm{H}^{\mathrm{Ar}}\right), 5.73-5.63\left(\mathrm{~m}, 4 \mathrm{H}, \mathrm{O}-\mathrm{CH}_{2}-\mathrm{O}\right), 5.60-5.54(\mathrm{~m}, 1 \mathrm{H}, \mathrm{CH}=\mathrm{C}), 4.94(\mathrm{~d}$, $\left.J=5.0 \mathrm{~Hz}, 2 \mathrm{H}, \mathrm{CH}_{2}-\mathrm{N}\right), 4.90$ (sept., $\left.J=6.3 \mathrm{~Hz}, 2 \mathrm{H}, \mathrm{CH}\left(\mathrm{CH}_{3}\right)_{2}\right), 2.80(\mathrm{dd}, J=23.3,7.9 \mathrm{~Hz}$, $\left.2 \mathrm{H}, \mathrm{CH}_{2}-\mathrm{P}\right), 2.62\left(\mathrm{t}, \mathrm{J}=7.8 \mathrm{~Hz}, 2 \mathrm{H}, \mathrm{Ar}-\mathrm{CH}_{2}-\mathrm{CH}_{2}-\mathrm{CH}_{2}-\mathrm{CH}_{3}\right), 1.64-1.58\left(\mathrm{~m}, 3 \mathrm{H}, \mathrm{CH}_{3} ; 2 \mathrm{H}\right.$, Ar- $\left.\mathrm{CH}_{2}-\mathrm{CH}_{2}-\mathrm{CH}_{2}-\mathrm{CH}_{3}\right), 1.40-1.34\left(\mathrm{~m}, 2 \mathrm{H}, \mathrm{Ar}-\mathrm{CH}_{2}-\mathrm{CH}_{2}-\mathrm{CH}_{2}-\mathrm{CH}_{3}\right), 1.28(\mathrm{~d}, J=6.3 \mathrm{~Hz}, 12 \mathrm{H}$, $\left.\mathrm{CH}\left(\mathrm{CH}_{3}\right)_{2}\right), 0.92\left(\mathrm{t}, J=7.3 \mathrm{~Hz}, 3 \mathrm{H}, \mathrm{Ar}-\mathrm{CH}_{2}-\mathrm{CH}_{2}-\mathrm{CH}_{2}-\mathrm{CH}_{3}\right) .{ }^{13} \mathrm{C} \mathrm{NMR}\left(101 \mathrm{MHz}, \mathrm{CDCl}_{3}\right) \delta$ $153.2(\mathrm{C}=\mathrm{O}), 148.4\left(\mathrm{C}^{\mathrm{q}}, \mathrm{Ar}\right), 143.0\left(\mathrm{C}^{\mathrm{q}}, \mathrm{Ar}\right), 135.9,135.8(\mathrm{CH}=\mathrm{C}), 128.8\left(\mathrm{CH}_{\mathrm{Ar}}\right), 128.0\left(\mathrm{C}^{\mathrm{q}, \mathrm{Ar}}\right)$, $125.7\left(\mathrm{CH}^{\mathrm{Ar}}\right), 119.0\left(\mathrm{CH}^{\mathrm{Ar}}\right), 118.1,118.0(\mathrm{CH}=\mathrm{C}), 84.2,84.1\left(\mathrm{O}-\mathrm{CH}_{2}-\mathrm{O}\right), 73.4\left(\mathrm{CH}\left(\mathrm{CH}_{3}\right)_{2}\right)$, $57.8,57.8\left(\mathrm{CH}_{2}-\mathrm{N}\right), 35.4\left(\mathrm{Ar}-\mathrm{CH}_{2}-\mathrm{CH}_{2}-\mathrm{CH}_{2}-\mathrm{CH}_{3}\right), 33.5\left(\mathrm{Ar}-\mathrm{CH}_{2}-\mathrm{CH}_{2}-\mathrm{CH}_{2}-\mathrm{CH}_{3}\right), 27.8\left(\mathrm{CH}_{2}-\right.$ P), $26.4\left(\mathrm{CH}_{2}-\mathrm{P}\right), 22.3\left(\mathrm{Ar}-\mathrm{CH}_{2}-\mathrm{CH}_{2}-\mathrm{CH}_{2}-\mathrm{CH}_{3}\right), 21.6,21.6\left(\mathrm{CH}\left(\mathrm{CH}_{3}\right)_{2}\right), 14.2,14.2\left(\mathrm{CH}_{3}\right), 13.9$ $\left(\mathrm{Ar}-\mathrm{CH}_{2}-\mathrm{CH}_{2}-\mathrm{CH}_{2}-\mathrm{CH}_{3}\right) .{ }^{31} \mathrm{P} \mathrm{NMR}\left(162 \mathrm{MHz}, \mathrm{CDCl}_{3}\right) \delta 27.46$. HRMS (ESI): $\mathrm{m} / z$ [M+Na] ${ }^{+}$ calcd for $\mathrm{C}_{27} \mathrm{H}_{40} \mathrm{~N}_{3} \mathrm{NaO}_{9} \mathrm{P}: 604.23943$, found: 604.23935 .

[[(E)-4-[4-(4-Pentylphenyl)triazol-1-yl]-3-methyl-but-2-enyl]-(isopropoxycarbonyloxymethoxy)phosphoryl]oxymethyl isopropyl carbonate (11c)

The title compound was prepared from 10 (96 mg, $0.23 \mathrm{mmol})$ and 1-ethynyl-4penthylbenzene $(57 \mu \mathrm{L}, 0.29 \mathrm{mmol})$ following the general procedure $\mathrm{A}$; the resulting suspension was stirred for $2 \mathrm{~h}$ at $40{ }^{\circ} \mathrm{C}$. After purification on a silica gel column chromatography (EtOAc/PE, 4:6), the desired pure compound 11c (115 mg, 85\%) was obtained as a colorless oil. ${ }^{1} \mathrm{H}$ NMR $\left(400 \mathrm{MHz} \mathrm{CDCl}_{3}\right) \delta 7.76\left(\mathrm{~s}, 2 \mathrm{H}, \mathrm{H}^{\mathrm{Ar}}\right), 7.74\left(\mathrm{~s}, 1 \mathrm{H}, \mathrm{H}^{5}\right), 7.22$ $\left(\mathrm{d}, \mathrm{J}=7.8 \mathrm{~Hz}, 2 \mathrm{H}, \mathrm{H}^{\mathrm{Ar}}\right), 5.72-5.64\left(\mathrm{~m}, 4 \mathrm{H}, \mathrm{O}-\mathrm{CH}_{2}-\mathrm{O}\right), 5.61-5.56(\mathrm{~m}, 1 \mathrm{H}, \mathrm{CH}=\mathrm{C}), 4.94(\mathrm{~d}$, $\left.J=5.1 \mathrm{~Hz}, 2 \mathrm{H}, \mathrm{CH}_{2}-\mathrm{N}\right), 4.90$ (sept., $\left.J=6.2 \mathrm{~Hz}, 2 \mathrm{H}, \mathrm{CH}\left(\mathrm{CH}_{3}\right)_{2}\right), 2.80(\mathrm{dd}, J=23.1,7.8 \mathrm{~Hz}, 2 \mathrm{H}$, $\left.\mathrm{CH}_{2}-\mathrm{P}\right), 2.62\left(\mathrm{t}, \mathrm{J}=7.8 \mathrm{~Hz}, 2 \mathrm{H}, \mathrm{Ar}-\mathrm{CH}_{2}-\left(\mathrm{CH}_{2}\right)_{3}-\mathrm{CH}_{3}\right), 1.64-1.59\left(\mathrm{~m}, 3 \mathrm{H}, \mathrm{CH}_{3} ; 2 \mathrm{H}, \mathrm{Ar}-\mathrm{CH}_{2}-\right.$ $\left.\mathrm{CH}_{2}-\mathrm{CH}_{2}-\mathrm{CH}_{2}-\mathrm{CH}_{3}\right), 1.33-1.32\left(\mathrm{~m}, 4 \mathrm{H}, \mathrm{Ar}-\mathrm{CH}_{2}-\mathrm{CH}_{2}-\mathrm{CH}_{2}-\mathrm{CH}_{2}-\mathrm{CH}_{3}\right), 1.28(\mathrm{~d}, \mathrm{~J}=6.3 \mathrm{~Hz}$, $\left.12 \mathrm{H}, \mathrm{CH}\left(\mathrm{CH}_{3}\right)_{2}\right), 0.89\left(\mathrm{t}, \mathrm{J}=7.3 \mathrm{~Hz}, 3 \mathrm{H}, \mathrm{Ar}-\left(\mathrm{CH}_{2}\right)_{4}-\mathrm{CH}_{3}\right) .{ }^{13} \mathrm{C} \mathrm{NMR}\left(101 \mathrm{MHz}, \mathrm{CDCl}_{3}\right) \delta$ $153.2(\mathrm{C}=\mathrm{O}), 148.4\left(\mathrm{C}^{\mathrm{q}, \mathrm{Ar}}\right), 143.0\left(\mathrm{C}^{\mathrm{q}, \mathrm{Ar}}\right), 135.9,135.7(\mathrm{CH}=\mathrm{C}), 128.8\left(\mathrm{CH}_{\mathrm{Ar}}\right), 128.0\left(\mathrm{C}^{\mathrm{q}, \mathrm{Ar}}\right)$, $125.7\left(\mathrm{CH}^{\mathrm{Ar}}\right), 119.0\left(\mathrm{CH}^{\mathrm{Ar}}\right), 118.1,118.0(\mathrm{CH}=\mathrm{C}), 84.2,84.1\left(\mathrm{O}-\mathrm{CH}_{2}-\mathrm{O}\right), 73.4\left(\mathrm{CH}\left(\mathrm{CH}_{3}\right)_{2}\right)$, 57.8, $57.8\left(\mathrm{CH}_{2}-\mathrm{N}\right)$, $35.7\left(\mathrm{Ar}-\mathrm{CH}_{2}-\left(\mathrm{CH}_{2}\right)_{3}-\mathrm{CH}_{3}\right), 31.4,31.1\left(\mathrm{Ar}-\mathrm{CH}_{2}-\mathrm{CH}_{2}-\mathrm{CH}_{2}-\mathrm{CH}_{2}-\mathrm{CH}_{3}\right)$, $27.8\left(\mathrm{CH}_{2}-\mathrm{P}\right), 26.4\left(\mathrm{CH}_{2}-\mathrm{P}\right), 23.9\left(\mathrm{Ar}-\mathrm{CH}_{2}-\mathrm{CH}_{2}-\mathrm{CH}_{2}-\mathrm{CH}_{2}-\mathrm{CH}_{3}\right), 22.5\left(\mathrm{Ar}-\left(\mathrm{CH}_{2}\right)_{3} \mathrm{CH}_{2}-\mathrm{CH}_{3}\right)$, 21.6, 21.6 $\left(\mathrm{CH}\left(\mathrm{CH}_{3}\right)_{2}\right), 14.2,14.2\left(\mathrm{CH}_{3}\right), 14.0\left(\mathrm{Ar}-\left(\mathrm{CH}_{2}\right)_{4}-\mathrm{CH}_{3}\right) .{ }^{31} \mathrm{P} \mathrm{NMR}\left(162 \mathrm{MHz}, \mathrm{CDCl}_{3}\right)$ $\delta$ 27.51. HRMS (ESI): $m / z$ [M+Na] ${ }^{+}$calcd for $\mathrm{C}_{28} \mathrm{H}_{42} \mathrm{~N}_{3} \mathrm{NaO}_{9} \mathrm{P}: 618.25508$, found: 618.25473. 
[[(E)-4-[4-(4-Hexylphenyl)triazol-1-yl]-3-methyl-but-2-enyl]-(isopropoxycarbonyloxymethoxy)phosphoryl]oxymethyl isopropyl carbonate (11d)

The title compound was prepared from $10(93 \mathrm{mg}, 0.22 \mathrm{mmol})$ and 1-ethynyl-4hexylbenzene $(60 \mu \mathrm{L} \mathrm{mg}, 0.29 \mathrm{mmol})$ following the general procedure $\mathrm{A}$; the resulting suspension was stirred for $2 \mathrm{~h}$ at $40^{\circ} \mathrm{C}$. After purification on a silica gel column chromatography (EtOAc/PE, 35:65), the desired pure compound 11d (112 mg, 84\%) was obtained as a yellow oil. ${ }^{1} \mathrm{H} \mathrm{NMR}\left(400 \mathrm{MHz}, \mathrm{CDCl}_{3}\right) \delta 7.75\left(\mathrm{~d}, J=5.4 \mathrm{~Hz}, 2 \mathrm{H}, \mathrm{H}^{\mathrm{Ar}}\right), 7.72(\mathrm{~s}, 1 \mathrm{H}$, $\left.\mathrm{H}^{5}\right), 7.20\left(\mathrm{~d}, J=7.8 \mathrm{~Hz}, 2 \mathrm{H}, \mathrm{H}^{\mathrm{Ar}}\right), 5.70-5.62\left(\mathrm{~m}, 4 \mathrm{H}, \mathrm{O}-\mathrm{CH}_{2}-\mathrm{O}\right), 5.59-5.53(\mathrm{~m}, 1 \mathrm{H}, \mathrm{CH}=\mathrm{C})$, $4.92\left(\mathrm{~d}, J=3.8 \mathrm{~Hz}, 2 \mathrm{H}, \mathrm{CH}_{2}-\mathrm{N}\right), 4.88$ (sept., $\left.J=6.2 \mathrm{~Hz}, 2 \mathrm{H}, \mathrm{CH}\left(\mathrm{CH}_{3}\right)_{2}\right), 2.78(\mathrm{dd}, J=23.1$, $\left.7.8 \mathrm{~Hz}, 2 \mathrm{H}, \mathrm{CH}_{2}-\mathrm{P}\right), 2.60\left(\mathrm{t}, J=7.8 \mathrm{~Hz}, 2 \mathrm{H}, \mathrm{Ar}-\mathrm{CH}_{2}-\left(\mathrm{CH}_{2}\right)_{4}-\mathrm{CH}_{3}\right), 1.62-1.56\left(\mathrm{~m}, 3 \mathrm{H}, \mathrm{CH}_{3}\right.$; $\left.2 \mathrm{H}, \mathrm{Ar}-\mathrm{CH}_{2}-\mathrm{CH}_{2}-\left(\mathrm{CH}_{2}\right)_{3} \mathrm{CH}_{3}\right), 1.33-1.25\left(\mathrm{~m}, 18 \mathrm{H}, \mathrm{Ar}-\mathrm{CH}_{2}-\mathrm{CH}_{2}-\left(\mathrm{CH}_{2}\right)_{3} \mathrm{CH}_{3}, \mathrm{CH}\left(\mathrm{CH}_{3}\right)_{2}\right)$, $0.86\left(\mathrm{t}, J=7.0 \mathrm{~Hz}, 3 \mathrm{H}, \mathrm{Ar}-\left(\mathrm{CH}_{2}\right)_{5}-\mathrm{CH}_{3}\right) .{ }^{13} \mathrm{C} \mathrm{NMR}\left(101 \mathrm{MHz}, \mathrm{CDCl}_{3}\right) \delta 153.2(\mathrm{C}=\mathrm{O}), 148.3$ $\left(\mathrm{C}^{\mathrm{q}, \mathrm{Ar}}\right), 143.0\left(\mathrm{C}^{\mathrm{q}, \mathrm{Ar}}\right), 135.9,135.8(\mathrm{CH}=\mathrm{C}), 128.8\left(\mathrm{CH}_{\mathrm{Ar}}\right), 128.0\left(\mathrm{C}^{\mathrm{q}, \mathrm{Ar}}\right), 125.7\left(\mathrm{CH}^{\mathrm{Ar}}\right), 119.1$ $\left(\mathrm{CH}^{\mathrm{Ar}}\right), 118.1,117.9(\mathrm{CH}=\mathrm{C}), 84.2,84.1\left(\mathrm{O}-\mathrm{CH}_{2}-\mathrm{O}\right), 73.4\left(\mathrm{CH}\left(\mathrm{CH}_{3}\right)_{2}\right), 57.8,57.7\left(\mathrm{CH}_{2}-\mathrm{N}\right)$, 35.7 (Ar- $\left.\mathrm{CH}_{2}-\left(\mathrm{CH}_{2}\right)_{4}-\mathrm{CH}_{3}\right), 31.7,31.3\left(\mathrm{Ar}-\mathrm{CH}_{2}-\mathrm{CH}_{2}-\left(\mathrm{CH}_{2}\right)_{3} \mathrm{CH}_{3}\right), 28.9\left(\mathrm{Ar}-\mathrm{CH}_{2}-\mathrm{CH}_{2}-\mathrm{CH}_{2}-\right.$ $\left.\mathrm{CH}_{2}-\mathrm{CH}_{2}-\mathrm{CH}_{3}\right), 27.8\left(\mathrm{CH}_{2}-\mathrm{P}\right), 26.4\left(\mathrm{CH}_{2}-\mathrm{P}\right), 23.9\left(\mathrm{Ar}-\mathrm{CH}_{2}-\mathrm{CH}_{2}-\mathrm{CH}_{2}-\mathrm{CH}_{2}-\mathrm{CH}_{2}-\mathrm{CH}_{3}\right), 22.6$ (Ar- $\left.\left(\mathrm{CH}_{2}\right)_{4} \mathrm{CH}_{2}-\mathrm{CH}_{3}\right), 21.6,21.6\left(\mathrm{CH}\left(\mathrm{CH}_{3}\right)_{2}\right), 14.2,14.21\left(\mathrm{CH}_{3}\right), 14.1\left(\mathrm{Ar}-\left(\mathrm{CH}_{2}\right)_{5}-\mathrm{CH}_{3}\right) .{ }^{31} \mathrm{P}$ NMR (162 MHz, $\left.\mathrm{CDCl}_{3}\right) \delta 27.50$. HRMS (ESI): $\mathrm{m} / z$ [M+Na] ${ }^{+}$calcd for $\mathrm{C}_{29} \mathrm{H}_{44} \mathrm{~N}_{3} \mathrm{NaO}_{9} \mathrm{P}$ : 632.27073, found: 632.27074 .

[[(E)-4-[4-(4-Heptylphenyl)triazol-1-yl]-3-methyl-but-2-enyl]-(isopropoxycarbonyloxymethoxy)phosphoryl]oxymethyl isopropyl carbonate (11e)

The title compound was prepared from $10(113 \mathrm{mg}, 0.27 \mathrm{mmol})$ and 1-ethynyl-4heptylbenzene $(78 \mu \mathrm{L}, 0.35 \mathrm{mmol})$ following the general procedure $\mathrm{A}$; the resulting suspension was stirred for $2 \mathrm{~h}$ at $40{ }^{\circ} \mathrm{C}$. After purification on a silica gel column chromatography (EtOAc/PE, 3:7), the desired pure compound 11e (151 mg, 91\%) was obtained as a yellow oil. ${ }^{1} \mathrm{H}$ NMR $\left(400 \mathrm{MHz}, \mathrm{CDCl}_{3}\right) \delta 7.76\left(\mathrm{~d}, J=2.4 \mathrm{~Hz}, 2 \mathrm{H}, \mathrm{H}^{\mathrm{Ar}}\right), 7.74\left(\mathrm{~s}, 1 \mathrm{H}, \mathrm{H}^{5}\right), 7.22$ $\left(\mathrm{d}, J=7.8 \mathrm{~Hz}, 2 \mathrm{H}, \mathrm{H}^{\mathrm{Ar}}\right), 5.72-5.64\left(\mathrm{~m}, 4 \mathrm{H}, \mathrm{O}-\mathrm{CH}_{2}-\mathrm{O}\right), 5.62-5.56(\mathrm{~m}, 1 \mathrm{H}, \mathrm{CH}=\mathrm{C}), 4.94(\mathrm{~d}$, $\left.J=3.8 \mathrm{~Hz}, 2 \mathrm{H}, \mathrm{CH}_{2}-\mathrm{N}\right), 4.89$ (sept., $\left.J=6.3 \mathrm{~Hz}, 2 \mathrm{H}, \mathrm{CH}\left(\mathrm{CH}_{3}\right)_{2}\right), 2.79(\mathrm{dd}, J=23.1,7.8 \mathrm{~Hz}$, $\left.2 \mathrm{H}, \mathrm{CH}_{2}-\mathrm{P}\right), 2.61\left(\mathrm{t}, J=7.8 \mathrm{~Hz}, 2 \mathrm{H}, \mathrm{Ar}-\mathrm{CH}_{2}-\left(\mathrm{CH}_{2}\right)_{5}-\mathrm{CH}_{3}\right), 1.64-1.58\left(\mathrm{~m}, 3 \mathrm{H}, \mathrm{CH}_{3} ; 2 \mathrm{H}\right.$, Ar- $\left.\mathrm{CH}_{2}-\mathrm{CH}_{2}-\left(\mathrm{CH}_{2}\right)_{4} \mathrm{CH}_{3}\right), 1.33-1.25\left(\mathrm{~m}, 2 \mathrm{H}, \mathrm{Ar}-\mathrm{CH}_{2}-\mathrm{CH}_{2}-\left(\mathrm{CH}_{2}\right)_{4} \mathrm{CH}_{3}, \mathrm{CH}\left(\mathrm{CH}_{3}\right)_{2}\right), 0.87$ $\left(\mathrm{t}, J=7.1 \mathrm{~Hz}, 3 \mathrm{H}, \mathrm{Ar}-\left(\mathrm{CH}_{2}\right)_{6}-\mathrm{CH}_{3}\right) .{ }^{13} \mathrm{C}$ NMR $\left(101 \mathrm{MHz}, \mathrm{CDCl}_{3}\right) \delta 153.2(\mathrm{C}=\mathrm{O}), 148.4$ $\left(\mathrm{C}^{\mathrm{q}, \mathrm{Ar}}\right), 143.0\left(\mathrm{C}^{\mathrm{q}, \mathrm{Ar}}\right), 135.9,135.8(\mathrm{CH}=\mathrm{C}), 128.8\left(\mathrm{CH}_{\mathrm{Ar}}\right), 128.0\left(\mathrm{C}^{\mathrm{q}, \mathrm{Ar}}\right), 125.6\left(\mathrm{CH}^{\mathrm{Ar}}\right), 119.0$ $\left(\mathrm{CH}^{\mathrm{Ar}}\right), 118.2,118.1(\mathrm{CH}=\mathrm{C}), 84.2,84.1\left(\mathrm{O}-\mathrm{CH}_{2}-\mathrm{O}\right), 73.4\left(\mathrm{CH}\left(\mathrm{CH}_{3}\right)_{2}\right), 57.9,57.8\left(\mathrm{CH}_{2}-\mathrm{N}\right)$, 35.7 ( $\left.\mathrm{Ar}-\mathrm{CH}_{2}-\left(\mathrm{CH}_{2}\right)_{5}-\mathrm{CH}_{3}\right), 31.8,31.4\left(\mathrm{Ar}-\mathrm{CH}_{2}-\mathrm{CH}_{2}-\left(\mathrm{CH}_{2}\right)_{4} \mathrm{CH}_{3}\right), 29.7,29.2,29.1\left(\mathrm{Ar}^{-} \mathrm{CH}_{2}-\right.$ $\left.\mathrm{CH}_{2}-\mathrm{CH}_{2}-\mathrm{CH}_{2}-\mathrm{CH}_{2}-\mathrm{CH}_{2}-\mathrm{CH}_{3}\right), 27.8\left(\mathrm{CH}_{2}-\mathrm{P}\right), 26.4\left(\mathrm{CH}_{2}-\mathrm{P}\right), 22.6\left(\mathrm{Ar}-\left(\mathrm{CH}_{2}\right)_{5} \mathrm{CH}_{2}-\mathrm{CH}_{3}\right)$, 21.6, $21.5\left(\mathrm{CH}\left(\mathrm{CH}_{3}\right)_{2}\right), 14.2,14.1\left(\mathrm{CH}_{3}\right), 14.1\left(\mathrm{Ar}-\left(\mathrm{CH}_{2}\right)_{6}-\mathrm{CH}_{3}\right) .{ }^{31} \mathrm{P} \mathrm{NMR}\left(162 \mathrm{MHz}, \mathrm{CDCl}_{3}\right)$ $\delta$ 27.46. HRMS (ESI): $m / z$ [M+H] ${ }^{+}$calcd for $\mathrm{C}_{30} \mathrm{H}_{47} \mathrm{~N}_{3} \mathrm{O} 9 \mathrm{P}: 624.30444$, found: 624.30373 .

[[(E)-4-(4-Cyclopropyltriazol-1-yl)-3-methyl-but-2-enyl]-(isopropoxycarbonyloxymethoxy)phosphoryl]oxymethyl isopropyl carbonate (11f)

The title compound was prepared from $10(94 \mathrm{mg}, 0.22 \mathrm{mmol})$ and cyclopropylacetylene $(24 \mu \mathrm{L}, 0.29 \mathrm{mmol})$ following the general procedure $\mathrm{A}$; the resulting suspension was stirred for $2 \mathrm{~h}$ at $40{ }^{\circ} \mathrm{C}$. After purification on a silica gel column chromatography (EtOAc/PE, 4:6), the desired pure compound $11 \mathrm{f}(86 \mathrm{mg}, 79 \%)$ was obtained as a colorless oil. ${ }^{1} \mathrm{H}$ NMR $\left(250 \mathrm{MHz}, \mathrm{CDCl}_{3}\right) \delta 7.23\left(\mathrm{~s}, 1 \mathrm{H}, \mathrm{H}^{5}\right), 5.72-5.62\left(\mathrm{~m}, 4 \mathrm{H}, \mathrm{O}-\mathrm{CH}_{2}-\mathrm{O}\right), 5.54-5.45$ $(\mathrm{m}, 1 \mathrm{H}, \mathrm{CH}=\mathrm{C}), 4.92$ (sept., $\left.J=6.2 \mathrm{~Hz}, 2 \mathrm{H}, \mathrm{CH}\left(\mathrm{CH}_{3}\right)_{2}\right), 4.83\left(\mathrm{~d}, J=4.1 \mathrm{~Hz}, 2 \mathrm{H}, \mathrm{CH}_{2}-\mathrm{N}\right)$, $2.76\left(\mathrm{dd}, J=23.1,7.8 \mathrm{~Hz}, 2 \mathrm{H}, \mathrm{CH}_{2}-\mathrm{P}\right), 2.00-1.89\left(\mathrm{~m}, 1 \mathrm{H}, \mathrm{CH}_{2} \mathrm{CHCH}_{2}\right), 1.59(\mathrm{~d}, J=5.5 \mathrm{~Hz}$, $\left.3 \mathrm{H}, \mathrm{CH}_{3}\right), 1.31\left(\mathrm{dd}, J=6.3,1.3 \mathrm{~Hz}, 12 \mathrm{H}, \mathrm{CH}\left(\mathrm{CH}_{3}\right)_{2}\right), 0.95-0.82\left(\mathrm{~m}, 4 \mathrm{H}, \mathrm{CH}_{2} \mathrm{CH}_{2}\right) .{ }^{13} \mathrm{C}$ NMR $\left(101 \mathrm{MHz}, \mathrm{CDCl}_{3}\right) \delta 153.2(\mathrm{C}=\mathrm{O}), 150.7(\mathrm{Cq}, \mathrm{Ar}), 136.01,135.9(\mathrm{CH}=\mathrm{C}), 119.4\left(\mathrm{CH}^{\mathrm{Ar}}\right)$, 117.8, 117.7 $(\mathrm{CH}=\mathrm{C}), 84.1,84.1\left(\mathrm{O}-\mathrm{CH}_{2}-\mathrm{O}\right), 73.4\left(\mathrm{CH}\left(\mathrm{CH}_{3}\right)_{2}\right)$, 57.6, $57.6\left(\mathrm{CH}_{2}-\mathrm{N}\right), 27.7,26.4$ $\left(\mathrm{CH}_{2}-\mathrm{P}\right), 21.7,21.6\left(\mathrm{CH}\left(\mathrm{CH}_{3}\right)_{2}\right), 14.2,14.1\left(\mathrm{CH}_{3}\right), 7.8\left(\mathrm{CH}_{2} \mathrm{CH}_{2}\right), 6.7\left(\mathrm{CH}_{2} \mathrm{CHCH}_{2}\right) .{ }^{31} \mathrm{P}$ NMR $\left(162 \mathrm{MHz}, \mathrm{CDCl}_{3}\right) \delta$ 27.6. HRMS (ESI): $m / z[\mathrm{M}+\mathrm{H}]^{+}$calcd for $\mathrm{C}_{20} \mathrm{H}_{33} \mathrm{~N}_{3} \mathrm{O}_{9} \mathrm{P}: 490.19489$, found: 490.19492 .

[[(E)-4-(4-tert-Butyltriazol-1-yl)-3-methyl-but-2-enyl]-(isopropoxycarbonyloxymethoxy) phosphoryl]oxymethyl isopropyl carbonate (11g) 
The title compound was prepared from 10 (98 $\mathrm{mg}, 0.23 \mathrm{mmol})$ and 3,3-dimethyl-1butyne $(37 \mu \mathrm{L}, 0.30 \mathrm{mmol})$ following the general procedure $\mathrm{A}$; the resulting suspension was stirred for $24 \mathrm{~h}$ at $40{ }^{\circ} \mathrm{C}$. After purification on a silica gel column chromatography (EtOAc/PE, 6:4), the desired pure compound 11g (56 mg, 48\%) was obtained as a colorless oil. ${ }^{1} \mathrm{H}$ NMR $\left(400 \mathrm{MHz} \mathrm{CDCl}_{3}\right) \delta 7.25\left(\mathrm{~s}, 1 \mathrm{H}, \mathrm{H}^{5}\right), 5.71-5.62\left(\mathrm{~m}, 4 \mathrm{H}, \mathrm{O}-\mathrm{CH}_{2}-\mathrm{O}\right), 5.51-5.45$ $(\mathrm{m}, 1 \mathrm{H}, \mathrm{CH}=\mathrm{C}), 4.92$ (sept., $\left.J=6.2 \mathrm{~Hz}, 2 \mathrm{H}, \mathrm{CH}\left(\mathrm{CH}_{3}\right)_{2}\right), 4.85\left(\mathrm{~d}, J=3.9 \mathrm{~Hz}, 2 \mathrm{H}, \mathrm{CH}_{2}-\mathrm{N}\right), 2.76$ $\left(\mathrm{dd}, J=23.1,7.8 \mathrm{~Hz}, 2 \mathrm{H}, \mathrm{CH}_{2}-\mathrm{P}\right), 1.60\left(\mathrm{~d}, J=4.5 \mathrm{~Hz}, 3 \mathrm{H}, \mathrm{CH}_{3}\right), 1.33\left(\mathrm{~s}, 9 \mathrm{H}, \mathrm{C}(\mathrm{CH})_{3}\right), 1.31(\mathrm{~d}$, $\left.J=6.3, \mathrm{~Hz}, 12 \mathrm{H}, \mathrm{CH}\left(\mathrm{CH}_{3}\right)_{2}\right) .{ }^{13} \mathrm{C} \mathrm{NMR}\left(101 \mathrm{MHz}, \mathrm{CDCl}_{3}\right) \delta 158.2\left(\mathrm{C}^{\mathrm{q}, \mathrm{Ar}}\right), 153.1(\mathrm{C}=\mathrm{O}), 136.1$, $136.0(\mathrm{CH}=\mathrm{C}), 118.4\left(\mathrm{CH}^{\mathrm{Ar}}\right), 117.6,117.5(\mathrm{CH}=\mathrm{C}), 84.2,84.1\left(\mathrm{O}-\mathrm{CH}_{2}-\mathrm{O}\right), 73.4\left(\mathrm{CH}\left(\mathrm{CH}_{3}\right)_{2}\right)$, 57.6, $57.5\left(\mathrm{CH}_{2}-\mathrm{N}\right), 30.8\left(\mathrm{C}(\mathrm{CH})_{3}\right), 30.3\left(\mathrm{C}(\mathrm{CH})_{3}\right), 27.7,26.3\left(\mathrm{CH}_{2}-\mathrm{P}\right), 21.6,21.5\left(\mathrm{CH}\left(\mathrm{CH}_{3}\right)_{2}\right)$, 14.3, $14.2\left(\mathrm{CH}_{3}\right) .{ }^{31} \mathrm{P}$ NMR (162 $\left.\mathrm{MHz}, \mathrm{CDCl}_{3}\right) \delta 27.62$. HRMS (ESI): $m / z[\mathrm{M}+\mathrm{H}]^{+}$calcd for $\mathrm{C}_{21} \mathrm{H}_{37} \mathrm{~N}_{3} \mathrm{O}_{9} \mathrm{P}: 506.22619$, found: 506.22601.

[[(E)-4-[4-(Hydroxymethyl)triazol-1-yl]-3-methyl-but-2-enyl]-(isopropoxycarbonyloxymethoxy)phosphoryl] oxymethyl isopropyl carbonate (11h)

The title compound was prepared from 10 (105 mg, $0.25 \mathrm{mmol})$ and propargyl alcohol $(19 \mu \mathrm{L}, 0.32 \mathrm{mmol})$ following the general procedure $\mathrm{A}$; the resulting suspension was stirred for $24 \mathrm{~h}$ at $40{ }^{\circ} \mathrm{C}$. After purification on a silica gel column chromatography $\left(\mathrm{MeOH} / \mathrm{CH}_{2} \mathrm{Cl}_{2}\right.$, 5/95), the desired pure compound $11 \mathrm{~h}(84 \mathrm{mg}, 71 \%)$ was obtained as a yellow oil. ${ }^{1} \mathrm{H}$ NMR $\left(400 \mathrm{MHz}, \mathrm{CDCl}_{3}\right) \delta 7.55\left(\mathrm{~s}, 1 \mathrm{H}, \mathrm{H}^{5}\right), 5.67-5.59\left(\mathrm{~m}, 4 \mathrm{H}, \mathrm{O}-\mathrm{CH}_{2}-\mathrm{O}\right), 5.49-5.44(\mathrm{~m}, 1 \mathrm{H}$, $\left.\mathrm{CH}=\mathrm{C}), 4.92-4.86\left(\mathrm{~m}, 4 \mathrm{H}, \mathrm{CH}\left(\mathrm{CH}_{3}\right)_{2}\right), \mathrm{CH}_{2}-\mathrm{N}\right), 4.75\left(\mathrm{~s}, 2 \mathrm{H}, \mathrm{CH}_{2} \mathrm{OH}\right), 2.74(\mathrm{dd}, \mathrm{J}=23.1$, $\left.7.8 \mathrm{~Hz}, 2 \mathrm{H}, \mathrm{CH}_{2}-\mathrm{P}\right), 1.57\left(\mathrm{~d}, J=4.6 \mathrm{~Hz}, 3 \mathrm{H}, \mathrm{CH}_{3}\right), 1.28\left(\mathrm{~d}, \mathrm{~J}=5.6, \mathrm{~Hz}, 12 \mathrm{H}, \mathrm{CH}\left(\mathrm{CH}_{3}\right)_{2}\right) .{ }^{13} \mathrm{C}$ NMR $\left(101 \mathrm{MHz}, \mathrm{CDCl}_{3}\right) \delta 153.2(\mathrm{C}=\mathrm{O}), 135.7,135.6(\mathrm{CH}=\mathrm{C}), 121.5\left(\mathrm{CH}^{\mathrm{Ar}}\right), 118.1,118.0$ $(\mathrm{CH}=\mathrm{C}), 84.1,84.0\left(\mathrm{O}-\mathrm{CH}_{2}-\mathrm{O}\right), 73.5\left(\mathrm{CH}\left(\mathrm{CH}_{3}\right)_{2}\right), 57.7,57.6\left(\mathrm{CH}_{2}-\mathrm{N}\right), 56.5\left(\mathrm{CH}_{2} \mathrm{OH}\right), 27.7$, $26.3\left(\mathrm{CH}_{2}-\mathrm{P}\right), 21.6,21.5\left(\mathrm{CH}\left(\mathrm{CH}_{3}\right)_{2}\right), 14.3,14.2\left(\mathrm{CH}_{3}\right) .{ }^{31} \mathrm{P} \mathrm{NMR}\left(162 \mathrm{MHz}, \mathrm{CDCl}_{3}\right) \delta 27.40$. HRMS (ESI): $m / z$ [M+Na] ${ }^{+}$calcd for $\mathrm{C}_{18} \mathrm{H}_{30} \mathrm{~N}_{3} \mathrm{NaO}_{10} \mathrm{P}: 502.156102$, found: 502.155885 .

[[(E)-4-(4-Formyltriazol-1-yl)-3-methyl-but-2-enyl]-(isopropoxycarbonyloxymethoxy) phosphoryl]oxymethyl isopropyl carbonate (11i)

The title compound was prepared from 10 (82 $\mathrm{mg}, 0.19 \mathrm{mmol})$ and 3,3-diethoxy-1propyne ( $36 \mu \mathrm{L}, 0.25 \mathrm{mmol}$ ) following the general procedure A; the resulting suspension was stirred for $2 \mathrm{~h}$ at $40{ }^{\circ} \mathrm{C}$. After purification on a silica gel column chromatography (EtOAc/PE, 6/4), the desired pure compound 11i (19 mg, 21\%) was obtained as a colorless oil. ${ }^{1} \mathrm{H}$ NMR $\left(400 \mathrm{MHz} \mathrm{CDCl}_{3}\right) \delta 10.14(\mathrm{~s}, 1 \mathrm{H}, \mathrm{CHO}), 8.14\left(\mathrm{~s}, 1 \mathrm{H}, \mathrm{H}^{5}\right), 5.71-5.63(\mathrm{~m}, 4 \mathrm{H}$, O-CH $2-\mathrm{O}$ ), 5.60-5.57 (m, 1H, CH=C), 4.98 (d, J = 3.9 Hz, 2H, $\left.\mathrm{CH}_{2}-\mathrm{N}\right), 4.92$ (sept., $J=6.2 \mathrm{~Hz}$, $\left.2 \mathrm{H}, \mathrm{CH}\left(\mathrm{CH}_{3}\right)_{2}\right), 2.78\left(\mathrm{dd}, \mathrm{J}=23.3,7.8 \mathrm{~Hz}, 2 \mathrm{H}, \mathrm{CH}_{2}-\mathrm{P}\right), 1.63\left(\mathrm{~d}, \mathrm{~J}=4.8 \mathrm{~Hz}, 3 \mathrm{H}, \mathrm{CH}_{3}\right), 1.31(\mathrm{~d}$, $\left.J=6.2 \mathrm{~Hz}, 12 \mathrm{H}, \mathrm{CH}\left(\mathrm{CH}_{3}\right)_{2}\right) .{ }^{13} \mathrm{C} \mathrm{NMR}\left(101 \mathrm{MHz}, \mathrm{CDCl}_{3}\right) \delta 184.9(\mathrm{CHO}), 153.1(\mathrm{C}=\mathrm{O}), 148.0$ $\left(\mathrm{C}^{\mathrm{q}}, \mathrm{Ar}\right), 134.8,134.6(\mathrm{CH}=\mathrm{C}), 125.2\left(\mathrm{CH}^{\mathrm{Ar}}\right), 119.5,119.4(\mathrm{CH}=\mathrm{C}), 84.2,84.1\left(\mathrm{O}-\mathrm{CH}_{2}-\mathrm{O}\right), 73.5$ $\left(\mathrm{CH}\left(\mathrm{CH}_{3}\right)_{2}\right)$, 58.1, $58.0\left(\mathrm{CH}_{2}-\mathrm{N}\right), 27.8,26.4\left(\mathrm{CH}_{2}-\mathrm{P}\right), 21.6,21.5\left(\mathrm{CH}\left(\mathrm{CH}_{3}\right)_{2}\right), 14.3,14.2\left(\mathrm{CH}_{3}\right)$. ${ }^{31} \mathrm{P}$ NMR (162 MHz, $\left.\mathrm{CDCl}_{3}\right) \delta 27.04$. HRMS (ESI): $m / z[\mathrm{M}+\mathrm{H}]^{+}$calcd for $\mathrm{C}_{18} \mathrm{H}_{29} \mathrm{~N}_{3} \mathrm{O}_{10} \mathrm{P}$ : 478.158507, found: 478.158468 .

[[(E)-4-(4-Carbamoyltriazol-1-yl)-3-methyl-but-2-enyl]-(isopropoxycarbonyloxymethoxy)phosphoryl]oxymethyl isopropyl carbonate (11j)

The title compound was prepared from $10(106 \mathrm{mg}, 0.25 \mathrm{mmol})$ and propiolamide (22 $\mathrm{mg}, 0.33 \mathrm{mmol}$ ) following the general procedure A; the resulting suspension was stirred for $14 \mathrm{~h}$ at $40{ }^{\circ} \mathrm{C}$. After purification on a silica gel column chromatography $\left(\mathrm{MeOH} / \mathrm{CH}_{2} \mathrm{Cl}_{2}\right.$, 3/97), the desired pure compound $\mathbf{1 1 j}(96 \mathrm{mg}, 78 \%)$ was obtained as a colorless oil. ${ }^{1} \mathrm{H}$ NMR $\left(400 \mathrm{MHz}\right.$, Acetone- $\left.\mathrm{d}_{6}\right) \delta 8.31\left(\mathrm{~s}, 1 \mathrm{H}, \mathrm{H}^{5}\right), 7.38(\mathrm{~s}, 1 \mathrm{H}, \mathrm{NH}), 6.78(\mathrm{~s}, 1 \mathrm{H}, \mathrm{NH}), 5.70-5.63$ (m, 4H, O-CH $-\mathrm{O}), 5.59-5.57(\mathrm{~m}, 1 \mathrm{H}, \mathrm{CH}=\mathrm{C}), 5.08\left(\mathrm{~d}, \mathrm{~J}=4.0 \mathrm{~Hz}, 2 \mathrm{H}, \mathrm{CH}_{2}-\mathrm{N}\right), 4.91$ (sept., $\left.J=6.2 \mathrm{~Hz}, 2 \mathrm{H}, \mathrm{CH}\left(\mathrm{CH}_{3}\right)_{2}\right), 2.84\left(\mathrm{dd}, J=22.4,7.9 \mathrm{~Hz}, 2 \mathrm{H}, \mathrm{CH}_{2}-\mathrm{P}\right), 1.66(\mathrm{~d}, J=3.9 \mathrm{~Hz}$, $\left.3 \mathrm{H}, \mathrm{CH}_{3}\right), 1.29\left(\mathrm{~d}, \mathrm{~J}=6.3 \mathrm{~Hz}, 12 \mathrm{H}, \mathrm{CH}\left(\mathrm{CH}_{3}\right)_{2}\right) .{ }^{13} \mathrm{C} \mathrm{NMR}(101 \mathrm{MHz}$, Acetone-d 6$) \delta 161.6$ $\left(\mathrm{NH}_{2} \mathrm{C}=\mathrm{O}\right), 153.1(\mathrm{C}=\mathrm{O}), 143.4\left(\mathrm{C}^{\mathrm{q}, \mathrm{Ar}}\right), 135.4,135.3(\mathrm{CH}=\mathrm{C}), 126.0\left(\mathrm{CH}^{\mathrm{Ar}}\right), 118.4,118.3$ $(\mathrm{CH}=\mathrm{C}), 84.2,84.1\left(\mathrm{O}-\mathrm{CH}_{2}-\mathrm{O}\right), 72.8\left(\mathrm{CH}\left(\mathrm{CH}_{3}\right)_{2}\right)$, 57.2, 57.1 $\left(\mathrm{CH}_{2}-\mathrm{N}\right), 27.3,25.9\left(\mathrm{CH}_{2}-\mathrm{P}\right)$, $20.9\left(\mathrm{CH}\left(\mathrm{CH}_{3}\right)_{2}\right), 13.6,13.5\left(\mathrm{CH}_{3}\right) .{ }^{31} \mathrm{P} \mathrm{NMR}\left(162 \mathrm{MHz}, \mathrm{CDCl}_{3}\right) \delta 27.05$. HRMS (ESI): $\mathrm{m} / z$ $[\mathrm{M}+\mathrm{H}]^{+}$calcd for $\mathrm{C}_{18} \mathrm{H}_{30} \mathrm{~N}_{4} \mathrm{O}_{10} \mathrm{P}: 493.169406$, found: 493.169337 . 
[[(E)-4-(4-Octanoylaminomethyltriazol-1-yl)-3-methyl-but-2-enyl]-(isopropoxycarbonyloxymethoxy)phosphoryl]oxymethyl isopropyl carbonate (11k)

The title compound was prepared from $10(109 \mathrm{mg}, 0.26 \mathrm{mmol})$ and $N-N$ (prop-2yn-1-yl)octanamide ( $56 \mathrm{mg}, 0.33 \mathrm{mmol}$ ) following the general procedure A; the resulting suspension was stirred for $24 \mathrm{~h}$ at $40{ }^{\circ} \mathrm{C}$. After purification on a silica gel column chromatography ( $\left.\mathrm{MeOH} / \mathrm{CH}_{2} \mathrm{Cl}_{2}, 3 / 97\right)$, the desired pure compound $11 \mathrm{k}(147 \mathrm{mg}, 94 \%)$ was obtained as a yellowish oil. ${ }^{1} \mathrm{H}$ NMR $\left(400 \mathrm{MHz}, \mathrm{CDCl}_{3}\right) \delta 7.51\left(\mathrm{~s}, 1 \mathrm{H}, \mathrm{H}^{5}\right), 6.20(\mathrm{~s}, 1 \mathrm{H}$, $\mathrm{NH}), 5.70-5.62\left(\mathrm{~m}, 4 \mathrm{H}, \mathrm{O}-\mathrm{CH}_{2}-\mathrm{O}\right), 5.52-5.47(\mathrm{~m}, 1 \mathrm{H}, \mathrm{CH}=\mathrm{C}), 4.92$ (sept., $J=6.3 \mathrm{~Hz}, 2 \mathrm{H}$, $\left.\mathrm{CH}\left(\mathrm{CH}_{3}\right)_{2}\right), 4.87\left(\mathrm{~d}, J=4.0 \mathrm{~Hz}, 2 \mathrm{H}, \mathrm{CH}_{2}-\mathrm{N}\right), 4.50\left(\mathrm{~d}, J=5.5 \mathrm{~Hz}, 2 \mathrm{H}, \mathrm{ArCH}_{2} \mathrm{NH}\right), 2.76$ $\left(\mathrm{dd}, J=23.3,7.9 \mathrm{~Hz}, 2 \mathrm{H}, \mathrm{CH}_{2}-\mathrm{P}\right), 2.18\left(\mathrm{t}, J=7.7 \mathrm{~Hz}, 2 \mathrm{H}, \mathrm{O}=\mathrm{CCH}_{2}\left(\mathrm{CH}_{2}\right)_{5} \mathrm{CH}_{3}\right), 1.65-1.59$ $\left(\mathrm{m}, 5 \mathrm{H}, \mathrm{CH}_{3} ; \mathrm{O}=\mathrm{CCH}_{2} \mathrm{CH}_{2}\left(\mathrm{CH}_{2}\right)_{4} \mathrm{CH}_{3}\right), 1.31\left(\mathrm{~d}, \mathrm{~J}=6.4 \mathrm{~Hz}, 12 \mathrm{H}, \mathrm{CH}\left(\mathrm{CH}_{3}\right)_{2}\right), 1.24-1.28$ $\left(\mathrm{m}, 8 \mathrm{H}, \mathrm{O}=\mathrm{CCH}_{2} \mathrm{CH}_{2}\left(\mathrm{CH}_{2}\right)_{4} \mathrm{CH}_{3}\right), 0.86\left(\mathrm{t}, J=6.9 \mathrm{~Hz}, 3 \mathrm{H}, \mathrm{O}=\mathrm{C}\left(\mathrm{CH}_{2}\right)_{6} \mathrm{CH}_{3}\right) .{ }^{13} \mathrm{C} \mathrm{NMR}$ $\left(101 \mathrm{MHz}, \mathrm{CDCl}_{3}\right) \delta 173.2(\mathrm{NHC}=\mathrm{O}), 153.2(\mathrm{C}=\mathrm{O}), 145.1\left(\mathrm{C}^{\mathrm{q}}, \mathrm{Ar}\right), 135.6,135.5(\mathrm{CH}=\mathrm{C}), 121.8$ $\left(\mathrm{CH}^{\mathrm{Ar}}\right), 118.2,118.1(\mathrm{CH}=\mathrm{C}), 84.6,84.1\left(\mathrm{O}-\mathrm{CH}_{2}-\mathrm{O}\right), 73.4\left(\mathrm{CH}\left(\mathrm{CH}_{3}\right)_{2}\right), 57.8,57.7\left(\mathrm{CH}_{2}-\right.$ $\mathrm{N}), 36.6\left(\mathrm{ArCH}_{2} \mathrm{NH}\right), 35.0\left(\mathrm{O}=\mathrm{CCH}_{2}\left(\mathrm{CH}_{2}\right)_{5} \mathrm{CH}_{3}\right), 31.7\left(\mathrm{O}=\mathrm{CCH}_{2} \mathrm{CH}_{2}\left(\mathrm{CH}_{2}\right)_{4} \mathrm{CH}_{3}, 29.3\right.$ $\left(\mathrm{O}=\mathrm{CCH}_{2} \mathrm{CH}_{2} \mathrm{CH}_{2}\left(\mathrm{CH}_{2}\right)_{3} \mathrm{CH}_{3}\right), 29.0\left(\mathrm{O}=\mathrm{C}\left(\mathrm{CH}_{2}\right)_{3} \mathrm{CH}_{2} \mathrm{CH}_{2} \mathrm{CH}_{2} \mathrm{CH}_{3}\right), 27.8\left(\mathrm{CH}_{2}-\mathrm{P}\right), 26.4$ $\left(\mathrm{CH}_{2}-\mathrm{P}\right), 25.6\left(\mathrm{O}=\mathrm{C}\left(\mathrm{CH}_{2}\right)_{4} \mathrm{CH}_{2} \mathrm{CH}_{2} \mathrm{CH}_{3}\right), 22.6\left(\mathrm{O}=\mathrm{C}\left(\mathrm{CH}_{2}\right)_{5} \mathrm{CH}_{2} \mathrm{CH}_{3}\right)$, 21.6, $21.6\left(\mathrm{CH}\left(\mathrm{CH}_{3}\right)_{2}\right.$, 14.3, $14.2\left(\mathrm{CH}_{3}\right), 14.1\left(\mathrm{O}=\mathrm{C}\left(\mathrm{CH}_{2}\right)_{6} \mathrm{CH}_{3}\right) .{ }^{31} \mathrm{P} \mathrm{NMR}\left(162 \mathrm{MHz}, \mathrm{CDCl}_{3}\right) \delta$ 27.31. HRMS (ESI): $m / z$ [M+Na] $]^{+}$calcd for $\mathrm{C}_{26} \mathrm{H}_{45} \mathrm{~N}_{4} \mathrm{NaO}_{10} \mathrm{P}: 627.276551$, found: 627.275980 .

[[(E)-4-(4-Nitrophenyltriazol-1-yl)-3-methyl-but-2-enyl]-(isopropoxycarbonyloxymethoxy)phosphoryl]oxymethyl isopropyl carbonate (111)

The title compound was prepared from $10(100 \mathrm{mg}, 0.24 \mathrm{mmol})$ and 1-ethynyl-4nitrobenzene $(45 \mathrm{mg}, 0.31 \mathrm{mmol})$ following the general procedure $\mathrm{A}$; the resulting suspension was stirred for $2 \mathrm{~h}$ at $40{ }^{\circ} \mathrm{C}$. After purification on a silica gel column chromatography (EtOAc/PE, 5/5), the desired pure compound $111(93 \mathrm{mg}, 69 \%)$ was obtained as a yellowish oil. ${ }^{1} \mathrm{H}$ NMR $\left(400 \mathrm{MHz}, \mathrm{CDCl}_{3}\right) \delta 8.28\left(\mathrm{~d}, J=8.5 \mathrm{~Hz}, 2 \mathrm{H}, \mathrm{H}^{\mathrm{Ar}}\right), 8.04(\mathrm{~d}, J=8.5 \mathrm{~Hz}, 2 \mathrm{H}$, $\left.\mathrm{H}^{\mathrm{Ar}}\right), 8.00\left(\mathrm{~s}, 1 \mathrm{H}, \mathrm{H}^{5}\right), 5.73-5.60\left(\mathrm{~m}, 5 \mathrm{H}, \mathrm{O}-\mathrm{CH}_{2}-\mathrm{O}, \mathrm{CH}=\mathrm{C}\right), 4.98\left(\mathrm{~d}, J=3.7 \mathrm{~Hz}, 2 \mathrm{H}, \mathrm{CH}_{2}-\mathrm{N}\right)$, 4.89 (sept., $\left.J=6.4 \mathrm{~Hz}, 2 \mathrm{H}, \mathrm{CH}\left(\mathrm{CH}_{3}\right)_{2}\right), 2.81\left(\mathrm{dd}, J=23.2,7.9 \mathrm{~Hz}, 2 \mathrm{H}, \mathrm{CH}_{2}-\mathrm{P}\right), 1.66(\mathrm{~d}$, $\left.J=4.9 \mathrm{~Hz}, 3 \mathrm{H}, \mathrm{CH}_{3}\right), 1.28\left(\mathrm{~d}, J=6.2 \mathrm{~Hz}, 12 \mathrm{H}, \mathrm{CH}\left(\mathrm{CH}_{3}\right)_{2}\right) .{ }^{13} \mathrm{C} \mathrm{NMR}\left(101 \mathrm{MHz}, \mathrm{CDCl}_{3}\right) \delta$ $153.2(\mathrm{C}=\mathrm{O}), 147.3\left(\mathrm{C}^{\mathrm{q}, \mathrm{Ar}}\right), 146.1\left(\mathrm{C}^{\mathrm{q}, \mathrm{Ar}}\right), 137.0\left(\mathrm{C}^{\mathrm{q}, \mathrm{Ar}}\right), 135.3,135.2(\mathrm{CH}=\mathrm{C}), 126.2\left(\mathrm{CH}^{\mathrm{Ar}}\right)$, 124.2 ( $\left.\mathrm{CH}^{\mathrm{Ar}}\right), 121.0\left(\mathrm{CH}^{\mathrm{Ar}}\right), 119.1,119.0(\mathrm{CH}=\mathrm{C}), 84.2,84.1\left(\mathrm{O}-\mathrm{CH}_{2}-\mathrm{O}\right), 73.5\left(\mathrm{CH}\left(\mathrm{CH}_{3}\right)_{2}\right)$, 58.2, $58.1\left(\mathrm{CH}_{2}-\mathrm{N}\right), 27.8,\left(\mathrm{CH}_{2}-\mathrm{P}\right), 26.4\left(\mathrm{CH}_{2}-\mathrm{P}\right), 21.6,21.5\left(\mathrm{CH}\left(\mathrm{CH}_{3}\right)_{2}\right), 14.3,14.3\left(\mathrm{CH}_{3}\right)$. ${ }^{31} \mathrm{P}$ NMR $\left(162 \mathrm{MHz}, \mathrm{CDCl}_{3}\right) \delta 27.26$. HRMS (ESI): $m / z[\mathrm{M}+\mathrm{H}]^{+}$calcd for $\mathrm{C}_{23} \mathrm{H}_{32} \mathrm{~N}_{4} \mathrm{O}_{11} \mathrm{P}$ : 571.179971, found: 571.179797 .

1-[(E)-4-[Bis(isopropoxycarbonyloxymethoxy)phosphoryl]-2-methyl-but-2-enyl]triazole4-carboxylic acid (11m)

To a solution of propiolic acid $(49 \mu \mathrm{L}, 1.1$ equiv., $0.80 \mathrm{mmol})$ and $(E)$-4-Azido-3-methylbut-2-enyl-bis(POC)phosphonate 10 (307 mg, 1.0 equiv., $0.73 \mathrm{mmol}$ ) in anhydrous $\mathrm{CH}_{2} \mathrm{Cl}_{2}$ $(10 \mathrm{~mL})$ was added 2-nitrophenylboronic acid $(25 \mathrm{mg}, 0.21$ equiv., $0.15 \mathrm{mmol})$ at room temperature. The solution was stirred for $42 \mathrm{~h}$ at room temperature. After evaporation of the solvent, the residue was purified by silica gel chromatography (MeOH/EtOAc, 1/9) to give compound $11 \mathrm{~m}(203 \mathrm{mg}, 57 \%)$ as a colorless oil. ${ }^{1} \mathrm{H}$ NMR $\left(400 \mathrm{MHz}, \mathrm{CD}_{3} \mathrm{OD}\right) \delta$ $8.28\left(\mathrm{~s}, 1 \mathrm{H}, \mathrm{H}^{5}\right), 5.72-5.64\left(\mathrm{~m}, 4 \mathrm{H}, \mathrm{O}-\mathrm{CH}_{2}-\mathrm{O}\right), 5.57-5.51(\mathrm{~m}, 1 \mathrm{H}, \mathrm{CH}=\mathrm{C}), 5.06(\mathrm{~d}, J=4.4 \mathrm{~Hz}$, $\left.2 \mathrm{H}, \mathrm{CH}_{2}-\mathrm{N}\right), 4.94$ (sept., $\left.J=6.4 \mathrm{~Hz}, 2 \mathrm{H}, \mathrm{CH}\left(\mathrm{CH}_{3}\right)_{2}\right), 2.91\left(\mathrm{dd}, J=23.2,7.9 \mathrm{~Hz}, 2 \mathrm{H}, \mathrm{CH}_{2}-\mathrm{P}\right)$, $1.67\left(\mathrm{~d}, J=4.8 \mathrm{~Hz}, 3 \mathrm{H}, \mathrm{CH}_{3}\right), 1.33\left(\mathrm{~d}, J=6.2 \mathrm{~Hz}, 12 \mathrm{H}, \mathrm{CH}\left(\mathrm{CH}_{3}\right)_{2}\right) .{ }^{13} \mathrm{C} \mathrm{NMR}(101 \mathrm{MHz}$, $\left.\mathrm{CD}_{3} \mathrm{OD}\right) \delta 153.2(\mathrm{C}=\mathrm{O}), 136.0,135.8(\mathrm{CH}=\mathrm{C}), 126.7\left(\mathrm{CH}^{\mathrm{Ar}}\right), 117.5,117.3(\mathrm{CH}=\mathrm{C}), 84.4,84.3$ $\left(\mathrm{O}-\mathrm{CH}_{2}-\mathrm{O}\right), 73.1\left(\mathrm{CH}\left(\mathrm{CH}_{3}\right)_{2}\right)$, 57.2, $57.1\left(\mathrm{CH}_{2}-\mathrm{N}\right), 26.8,25.4\left(\mathrm{CH}_{2}-\mathrm{P}\right), 20.5\left(\mathrm{CH}\left(\mathrm{CH}_{3}\right)_{2}\right)$, 13.6, $13.1\left(\mathrm{CH}_{3}\right) .{ }^{31} \mathrm{P}$ NMR $\left(162 \mathrm{MHz}, \mathrm{CD}_{3} \mathrm{OD}\right) \delta 27.94$. HRMS (ESI): $\mathrm{m} / z[\mathrm{M}+\mathrm{H}]^{+}$calcd for $\mathrm{C}_{18} \mathrm{H}_{29} \mathrm{~N}_{3} \mathrm{O}_{11} \mathrm{P}: 494.153422$, found: 494.153404 .

Methyl-1-[(E)-4-[bis(isopropoxycarbonyloxymethoxy)phosphoryl]-2-methyl-but-2enyl]triazole-4-carboxylate (11n)

The title compound was prepared from $10(124 \mathrm{mg}, 0.29 \mathrm{mmol})$ and methyl propiolate ( $34 \mu \mathrm{L}, 0.38 \mathrm{mmol}$ ) using the general procedure $\mathrm{A}$; the resulting suspension was stirred for $2 \mathrm{~h}$ at $40{ }^{\circ} \mathrm{C}$. After purification on a silica gel column chromatography (EtOAc/PE, 
6/4), the desired pure compound $11 \mathrm{n}(92 \mathrm{mg}, 63 \%)$ was obtained as a colorless oil. ${ }^{1} \mathrm{H}$ NMR $\left(250 \mathrm{MHz}, \mathrm{CD}_{3} \mathrm{OD}\right) \delta 8.57\left(\mathrm{~s}, 1 \mathrm{H}, \mathrm{H}^{5}\right), 5.79-5.69\left(\mathrm{~m}, 4 \mathrm{H}, \mathrm{O}-\mathrm{CH}_{2}-\mathrm{O}\right), 5.65-5.56(\mathrm{~m}$, $1 \mathrm{H}, \mathrm{CH}=\mathrm{C}), 5.14\left(\mathrm{~d}, J=4.2 \mathrm{~Hz}, 2 \mathrm{H}, \mathrm{CH}_{2}-\mathrm{N}\right), 4.99$ (sept., $\left.J=6.4 \mathrm{~Hz}, 2 \mathrm{H}, \mathrm{CH}\left(\mathrm{CH}_{3}\right)_{2}\right), 4.00$ $\left(\mathrm{s}, 3 \mathrm{H}, \mathrm{OCH}_{3}\right), 2.97\left(\mathrm{dd}, J=23.2,7.9 \mathrm{~Hz}, 2 \mathrm{H}, \mathrm{CH}_{2}-\mathrm{P}\right), 1.74\left(\mathrm{~d}, J=4.7 \mathrm{~Hz}, 3 \mathrm{H}, \mathrm{CH}_{3}\right), 1.39(\mathrm{~d}$, $\left.J=6.2 \mathrm{~Hz}, 12 \mathrm{H}, \mathrm{CH}\left(\mathrm{CH}_{3}\right)_{2}\right) \cdot{ }^{13} \mathrm{C}$ NMR $\left(101 \mathrm{MHz}, \mathrm{CDCl}_{3}\right) \delta 161.0(\mathrm{O}=\mathrm{C}-\mathrm{OMe}), 153.1(\mathrm{C}=\mathrm{O})$, $140.3\left(\mathrm{C}^{\mathrm{q}}, \mathrm{Ar}\right), 135.1,134.9(\mathrm{CH}=\mathrm{C}), 127.4\left(\mathrm{CH}^{\mathrm{Ar}}\right), 119.1,118.9(\mathrm{CH}=\mathrm{C}), 84.2,84.1\left(\mathrm{O}-\mathrm{CH}_{2}-\mathrm{O}\right)$, $73.4\left(\mathrm{CH}\left(\mathrm{CH}_{3}\right)_{2}\right), 58.0,57.9\left(\mathrm{CH}_{2}-\mathrm{N}\right), 52.1\left(\mathrm{OCH}_{3}\right), 27.8,26.4\left(\mathrm{CH}_{2}-\mathrm{P}\right)$, , 21.6, $21.5\left(\mathrm{CH}\left(\mathrm{CH}_{3}\right)_{2}\right)$, 14.3, $14.2\left(\mathrm{CH}_{3}\right) .{ }^{31} \mathrm{P}$ NMR $\left(162 \mathrm{MHz}, \mathrm{CDCl}_{3}\right) \delta 27.19$. HRMS (ESI): $\mathrm{m} / z[\mathrm{M}+\mathrm{Na}]^{+}$calcd for $\mathrm{C}_{19} \mathrm{H}_{30} \mathrm{~N}_{3} \mathrm{NaO}_{11}$ P: 530.151016, found: 530.151002 .

Ethyl-1-[(E)-4-[bis(isopropoxycarbonyloxymethoxy)phosphoryl]-2-methyl-but-2-enyl] triazole-4-carboxylate (110)

The title compound was prepared from $10(120 \mathrm{mg}, 0.28 \mathrm{mmol})$ and methyl propiolate $(37 \mu \mathrm{L}, 0.37 \mathrm{mmol})$ using the general procedure $\mathrm{A}$; the resulting suspension was stirred for $2 \mathrm{~h}$ at $40{ }^{\circ} \mathrm{C}$. After purification on a silica gel column chromatography (EtOAc/PE, $5 / 5)$, the desired pure compound 110 (94 $\mathrm{mg}, 64 \%$ ) was obtained as a colorless oil. ${ }^{1} \mathrm{H}$ NMR $\left(400 \mathrm{MHz}, \mathrm{CD}_{3} \mathrm{OD}\right) \delta 8.53\left(\mathrm{~s}, 1 \mathrm{H}, \mathrm{H}^{5}\right), 5.74-5.66\left(\mathrm{~m}, 4 \mathrm{H}, \mathrm{O}_{-} \mathrm{CH}_{2}-\mathrm{O}\right), 5.59-5.54(\mathrm{~m}$, $1 \mathrm{H}, \mathrm{CH}=\mathrm{C}), 5.10\left(\mathrm{~d}, J=4.2 \mathrm{~Hz}, 2 \mathrm{H}, \mathrm{CH}_{2}-\mathrm{N}\right), 4.95$ (sept., $\left.J=6.3 \mathrm{~Hz}, 2 \mathrm{H}, \mathrm{CH}\left(\mathrm{CH}_{3}\right)_{2}\right), 4.43(\mathrm{q}$, $\left.J=7.1 \mathrm{~Hz}, 2 \mathrm{H}, \mathrm{OCH}_{2} \mathrm{CH}_{3}\right), 2.93\left(\mathrm{dd}, J=23.2,7.9 \mathrm{~Hz}, 2 \mathrm{H}, \mathrm{CH}_{2}-\mathrm{P}\right), 1.70(\mathrm{~d}, J=4.8 \mathrm{~Hz}, 3 \mathrm{H}$, $\left.\mathrm{CH}_{3}\right), 1.42\left(\mathrm{t}, J=7.1 \mathrm{~Hz}, 3 \mathrm{H}, \mathrm{OCH}_{2} \mathrm{CH}_{3}\right), 1.34\left(\mathrm{~d}, J=6.7 \mathrm{~Hz}, 12 \mathrm{H}, \mathrm{CH}\left(\mathrm{CH}_{3}\right)_{2}\right) .{ }^{13} \mathrm{C} \mathrm{NMR}$ $\left(101 \mathrm{MHz}, \mathrm{CD}_{3} \mathrm{OD}\right) \delta 161.5(\mathrm{O}=\mathrm{C}-\mathrm{OEt}), 153.2(\mathrm{C}=\mathrm{O}), 139.7\left(\mathrm{C}^{\mathrm{q}, \mathrm{Ar}}\right), 135.8,135.6(\mathrm{CH}=\mathrm{C}), 128.2$ $\left(\mathrm{CH}^{\mathrm{Ar}}\right), 117.9,117.8(\mathrm{CH}=\mathrm{C}), 84.3,84.2\left(\mathrm{O}-\mathrm{CH}_{2}-\mathrm{O}\right), 73.1\left(\mathrm{CH}\left(\mathrm{CH}_{3}\right)_{2}\right), 60.8\left(\mathrm{OCH}_{2} \mathrm{CH}_{3}\right), 57.2$, $57.1\left(\mathrm{CH}_{2}-\mathrm{N}\right), 26.8,25.4\left(\mathrm{CH}_{2}-\mathrm{P}\right), 20.5\left(\mathrm{CH}\left(\mathrm{CH}_{3}\right)_{2}\right), 13.2\left(\mathrm{OCH}_{2} \mathrm{CH}_{3}\right), 13.1,13.0\left(\mathrm{CH}_{3}\right) .{ }^{31} \mathrm{P}$ NMR (162 MHz, CD $\left.{ }_{3} \mathrm{OD}\right) \delta$ 27.92. HRMS (ESI): $\mathrm{m} / z$ [M+Na] ${ }^{+}$calcd for $\mathrm{C}_{20} \mathrm{H}_{32} \mathrm{~N}_{3} \mathrm{NaO}_{11} \mathrm{P}$ : 544.166666, found: 544.166837 .

[[(E)-4-(4-Methylcarbamoyltriazol-1-yl)-3-methyl-but-2-enyl]-(isopropoxycarbonyloxymethoxy)phosphoryl]oxymethyl isopropyl carbonate (11p)

The title compound was prepared from $10(121 \mathrm{mg}, 0.29 \mathrm{mmol})$ and $\mathrm{N}$-methylprop-2ynamide ( $31 \mathrm{mg}, 0.37 \mathrm{mmol}$ ) following the general procedure $\mathrm{A}$; the resulting suspension was stirred for $2 \mathrm{~h}$ at $40{ }^{\circ} \mathrm{C}$. After purification on a silica gel column chromatography $\left(\mathrm{MeOH} / \mathrm{CH}_{2} \mathrm{Cl}_{2}, 1 / 99\right)$, the desired pure compound $11 \mathrm{p}(118 \mathrm{mg}, 82 \%)$ was obtained as a colorless oil. ${ }^{1} \mathrm{H}$ NMR $\left(400 \mathrm{MHz}, \mathrm{CD}_{3} \mathrm{OD}\right) \delta 8.34\left(\mathrm{~s}, 1 \mathrm{H}, \mathrm{H}^{5}\right), 5.74-5.66\left(\mathrm{~m}, 4 \mathrm{H}, \mathrm{O}-\mathrm{CH}_{2}-\mathrm{O}\right)$, 5.58-5.52 (m, 1H, CH=C), $5.09\left(\mathrm{~d}, J=4.0 \mathrm{~Hz}, 2 \mathrm{H}, \mathrm{CH}_{2}-\mathrm{N}\right), 4.96$ (sept., $J=6.2 \mathrm{~Hz}, 2 \mathrm{H}$, $\left.\mathrm{CH}\left(\mathrm{CH}_{3}\right)_{2}\right), 2.98\left(\mathrm{~s}, 3 \mathrm{H}, \mathrm{NHCH}_{3}\right), 2.92\left(\mathrm{dd}, J=23.2,7.9 \mathrm{~Hz}, 2 \mathrm{H}, \mathrm{CH}_{2}-\mathrm{P}\right), 1.69(\mathrm{~d}, J=4.6 \mathrm{~Hz}$, $\left.3 \mathrm{H}, \mathrm{CH}_{3}\right), 1.35\left(\mathrm{~d}, J=6.3 \mathrm{~Hz}, 12 \mathrm{H}, \mathrm{CH}\left(\mathrm{CH}_{3}\right)_{2}\right) .{ }^{13} \mathrm{C} \mathrm{NMR}\left(101 \mathrm{MHz}, \mathrm{CD}_{3} \mathrm{OD}\right) \delta 161.7$ $\left(\mathrm{O}=\mathrm{C}-\mathrm{NHCH}_{3}\right), 153.2(\mathrm{C}=\mathrm{O}), 142.9\left(\mathrm{C}^{\mathrm{q}}, \mathrm{Ar}\right), 136.0,135.8(\mathrm{CH}=\mathrm{C}), 125.7\left(\mathrm{CH}^{\mathrm{Ar}}\right), 117.5,117.4$ $(\mathrm{CH}=\mathrm{C}), 84.4,84.3\left(\mathrm{O}-\mathrm{CH}_{2}-\mathrm{O}\right), 73.1\left(\mathrm{CH}\left(\mathrm{CH}_{3}\right)_{2}\right), 57.1,57.0\left(\mathrm{CH}_{2}-\mathrm{N}\right), 26.8,25.4\left(\mathrm{CH}_{2}-\mathrm{P}\right), 24.7$ $\left(\mathrm{NHCH}_{3}\right), 20.5\left(\mathrm{CH}\left(\mathrm{CH}_{3}\right)_{2}\right), 13.1,13.1\left(\mathrm{CH}_{3}\right) .{ }^{31} \mathrm{P} \mathrm{NMR}\left(162 \mathrm{MHz}, \mathrm{CD}_{3} \mathrm{OD}\right) \delta 27.91$. HRMS (ESI): $m / z[\mathrm{M}+\mathrm{Na}]^{+}$calcd for $\mathrm{C}_{19} \mathrm{H}_{31} \mathrm{~N}_{4} \mathrm{NaO}_{10} \mathrm{P}: 529.167001$, found: 529.166551 .

[[(E)-4-[4-(Ethylcarbamoyl)triazol-1-yl]-3-methyl-but-2-enyl]-(isopropoxycarbonyloxymethoxy)phosphoryl]oxymethyl isopropyl carbonate (11q)

The title compound was prepared from $10(115 \mathrm{mg}, 0.27 \mathrm{mmol})$ and N-ethylprop-2ynamide ( $34 \mathrm{mg}, 0.35 \mathrm{mmol}$ ) following the general procedure $\mathrm{A}$; the resulting suspension was stirred for $2 \mathrm{~h}$ at $40{ }^{\circ} \mathrm{C}$. After purification on a silica gel column chromatography $\left(\mathrm{MeOH} / \mathrm{CH}_{2} \mathrm{Cl}_{2}, 1 / 99\right)$, the desired pure compound $11 \mathrm{q}(128 \mathrm{mg}, 91 \%)$ was obtained as a colorless oil. ${ }^{1} \mathrm{H}$ NMR $\left(400 \mathrm{MHz}, \mathrm{CD}_{3} \mathrm{OD}\right) \delta 8.35\left(\mathrm{~s}, 1 \mathrm{H}, \mathrm{H}^{5}\right), 5.75-5.67\left(\mathrm{~m}, 4 \mathrm{H}, \mathrm{O}-\mathrm{CH}_{2}-\mathrm{O}\right)$, $5.59-5.53(\mathrm{~m}, 1 \mathrm{H}, \mathrm{CH}=\mathrm{C}), 5.09$ (d, $\left.J=4.0 \mathrm{~Hz}, 2 \mathrm{H}, \mathrm{CH}_{2}-\mathrm{N}\right), 4.96$ (sept., $J=6.2 \mathrm{~Hz}, 2 \mathrm{H}$, $\left.\mathrm{CH}\left(\mathrm{CH}_{3}\right)_{2}\right), 3.47\left(\mathrm{q}, J=7.2 \mathrm{~Hz}, 2 \mathrm{H}, \mathrm{NHCH}_{2} \mathrm{CH}_{3}\right), 2.93\left(\mathrm{dd}, J=23.1,7.9 \mathrm{~Hz}, 2 \mathrm{H}, \mathrm{CH}_{2}-\mathrm{P}\right)$, $1.70\left(\mathrm{~d}, J=4.7 \mathrm{~Hz}, 3 \mathrm{H}, \mathrm{CH}_{3}\right), 1.35\left(\mathrm{~d}, J=6.2 \mathrm{~Hz}, 12 \mathrm{H}, \mathrm{CH}\left(\mathrm{CH}_{3}\right)_{2}\right), 1.28(\mathrm{t}, J=7.2 \mathrm{~Hz}$, $\left.3 \mathrm{H}, \mathrm{NHCH}_{2} \mathrm{CH}_{3}\right) .{ }^{13} \mathrm{C} \mathrm{NMR}\left(101 \mathrm{MHz}, \mathrm{CD}_{3} \mathrm{OD}\right) \delta 160.8(\mathrm{O}=\mathrm{C}-\mathrm{NH}), 153.2(\mathrm{C}=\mathrm{O}), 142.99$ $\left(\mathrm{C}^{\mathrm{q}, \mathrm{Ar}}\right), 136.0,135.8(\mathrm{CH}=\mathrm{C}), 125.7\left(\mathrm{CH}^{\mathrm{Ar}}\right), 117.5,117.4(\mathrm{CH}=\mathrm{C}), 84.4,84.3\left(\mathrm{O}^{\left.-\mathrm{CH}_{2}-\mathrm{O}\right)}, 73.1\right.$ $\left(\mathrm{CH}\left(\mathrm{CH}_{3}\right)_{2}\right), 57.1,57.0\left(\mathrm{CH}_{2}-\mathrm{N}\right), 33.7\left(\mathrm{NHCH}_{2} \mathrm{CH}_{3}\right), 26.8,25.4\left(\mathrm{CH}_{2}-\mathrm{P}\right), 20.5\left(\mathrm{CH}\left(\mathrm{CH}_{3}\right)_{2}\right)$, $13.6\left(\mathrm{NHCH}_{2} \mathrm{CH}_{3}\right), 13.1,13.0\left(\mathrm{CH}_{3}\right) .{ }^{31} \mathrm{P}$ NMR $\left(162 \mathrm{MHz}, \mathrm{CD}_{3} \mathrm{OD}\right) \delta 27.91$. HRMS (ESI): $m / z[\mathrm{M}+\mathrm{Na}]^{+}$calcd for $\mathrm{C}_{20} \mathrm{H}_{33} \mathrm{~N}_{4} \mathrm{NaO}_{10} \mathrm{P}: 543.182651$, found: 543.182603 .

(E)-4-Hydroxy-3-methyl-but-2-enyl-(HDP/POC) phosphonate (13) 
To a solution of (HDP/POC) allylphosphonate (12) (1.00 g, 2.0 equiv., $1.94 \mathrm{mmol})$ and 2-methyl-2-propen-1-ol (8) $(81 \mu \mathrm{L}, 1.0$ equiv., $0.97 \mathrm{mmol})$ in dry $\mathrm{CH}_{2} \mathrm{Cl}_{2}(10 \mathrm{~mL})$, HoveydaGrubbs catalyst $(91 \mathrm{mg}, 15 \mathrm{~mol} \%, 0.15 \mathrm{mmol})$ was added. The catalyst addition was performed in five equal portions of $3 \mathrm{~mol} \%(18.20 \mathrm{mg}, 0.029 \mathrm{mmol})$ at $\mathrm{t}=0,3,6,9$ and $21 \mathrm{~h}$ over the course of the reaction. The solution was sonicated at $55{ }^{\circ} \mathrm{C}$ under nitrogen atmosphere for $24 \mathrm{~h}$. Volatiles were evaporated and the residue was purified by silica gel column chromatography (EtOAc/PE, 5/5) to give the desired phosphonate derivative 13 (480 mg, $88 \%$ ) as brown oil. ${ }^{1} \mathrm{H}$ NMR $\left(400 \mathrm{MHz}, \mathrm{CDCl}_{3}\right) \delta 5.67-5.59\left(\mathrm{~m}, 2 \mathrm{H}, \mathrm{O}-\mathrm{CH}_{2}-\mathrm{O}\right), 5.47-5.41(\mathrm{~m}$, $1 \mathrm{H}, \mathrm{CH}=\mathrm{C}), 4.92$ (sept., $\left.J=6.3 \mathrm{~Hz}, 1 \mathrm{H}, \mathrm{CH}\left(\mathrm{CH}_{3}\right)_{2}\right), 4.21-4.08\left(\mathrm{~m}, 2 \mathrm{H}, \mathrm{H}^{\mathrm{a}}\right), 4.02(\mathrm{~d}, J=5.0 \mathrm{~Hz}$, $\left.2 \mathrm{H}, \mathrm{CH}_{2}-\mathrm{OH}\right), 3.47\left(\mathrm{t}, J=6.2 \mathrm{~Hz}, 2 \mathrm{H}, \mathrm{H}^{\mathrm{c}}\right), 3.38\left(\mathrm{t}, J=6.7 \mathrm{~Hz}, 2 \mathrm{H}, \mathrm{CH}_{3}\left(\mathrm{CH}_{2}\right)_{14} \mathrm{CH}_{2}-\mathrm{O}\right)$, 2.67 (dd, $J=22.5,7.8 \mathrm{~Hz}, 2 \mathrm{H}, \mathrm{CH}_{2}-\mathrm{P}$ ), 1.90 (quint., $J=6.3 \mathrm{~Hz}, 2 \mathrm{H}, \mathrm{H}^{\mathrm{b}}$ ), 1.69 (dd, $J=4.3$, $\left.1.3 \mathrm{~Hz}, 3 \mathrm{H}, \mathrm{CH}_{3}\right), 1.54$ (quint., $\left.J=7.0 \mathrm{~Hz}, 2 \mathrm{H}, \mathrm{CH}_{3}\left(\mathrm{CH}_{2}\right)_{13} \mathrm{CH}_{2} \mathrm{CH}_{2}-\mathrm{O}\right), 1.32-1.24(\mathrm{~m}, 32 \mathrm{H}$, $\left.\mathrm{CH}_{3}\left(\mathrm{CH}_{2}\right)_{13} \mathrm{CH}_{2} \mathrm{CH}_{2} \mathrm{O}, \mathrm{CH}\left(\mathrm{CH}_{3}\right)_{2}\right), 0.87\left(\mathrm{t}, \mathrm{J}=6.7 \mathrm{~Hz}, 3 \mathrm{H}, \mathrm{CH}_{3}\left(\mathrm{CH}_{2}\right)_{15} \mathrm{O}\right) .{ }^{13} \mathrm{C} \mathrm{NMR}$ $\left(101 \mathrm{MHz} \mathrm{CDCl}_{3}\right) \delta 153.3(\mathrm{C}=\mathrm{O}), 140.8,140.7(\mathrm{CH}=\mathrm{C}), 112.6,112.5(\mathrm{CH}=\mathrm{C}), 84.4,84.3$ $\left(\mathrm{O}-\mathrm{CH}_{2}-\mathrm{O}\right), 73.1\left(\mathrm{CH}\left(\mathrm{CH}_{3}\right)_{2}\right), 71.2\left(\mathrm{CH}_{3}\left(\mathrm{CH}_{2}\right)_{14} \mathrm{CH}_{2}-\mathrm{O}\right), 68.1,68.0\left(\mathrm{CH}_{2}-\mathrm{OH}\right), 66.5,66.4$ $\left(C^{\mathrm{c}}\right), 63.3,63.2\left(\mathrm{C}^{\mathrm{a}}\right), 31.9,30.7,30.6\left(\mathrm{C}^{\mathrm{b}}\right), 29.7,29.5,29.4,27.1\left(\mathrm{CH}_{2}-\mathrm{P}\right), 26.2,25.7\left(\mathrm{CH}_{2}-\mathrm{P}\right)$, 22.7, $21.6\left(\mathrm{CH}\left(\mathrm{CH}_{3}\right)_{2}\right), 14.1\left(\mathrm{CH}_{3}\left(\mathrm{CH}_{2}\right)_{15} \mathrm{O}\right), 13.9,13.8\left(\mathrm{CH}_{3}\right) .{ }^{31} \mathrm{P} \mathrm{NMR}\left(162 \mathrm{MHz}, \mathrm{CDCl}_{3}\right) \delta$ 26.71. HRMS (ESI): $m / z[\mathrm{M}+\mathrm{H}]^{+}$calcd for $\mathrm{C}_{29} \mathrm{H}_{58} \mathrm{O}_{8} \mathrm{P}: 565.386382$, found: 565.385868 .

(E)-4-Azido-3-methyl-but-2-enyl-(HDP/POC) phosphonate (14)

To a solution of (E)-4-hydroxy-3-methyl-but-2-enyl-(HDP/POC)phosphonate 13 (277 mg, 1.0 equiv., $0.49 \mathrm{mmol})$ in anhydrous $\mathrm{CH}_{2} \mathrm{Cl}_{2}(5 \mathrm{~mL})$ were added dropwise methansulfonyl chloride ( $42 \mu \mathrm{L}, 1.1$ equiv., $0.54 \mathrm{mmol})$ and anhydrous triethylamine (75 $\mu \mathrm{L}, 1.1$ equiv., $0.54 \mathrm{mmol}$ ) at $0{ }^{\circ} \mathrm{C}$ under the argon. After $40 \mathrm{~min}$ stirring at room temperature, the mixture was diluted with $\mathrm{CH}_{2} \mathrm{Cl}_{2}$ and washed with water $(3 \times 10 \mathrm{~mL})$ and brine. The organic layer was dried over $\mathrm{MgSO}_{4}$, filtrated and concentrated in vacuo. The residue was directly used for the next step without further purification. To a solution of the above product in anhydrous DMF (8 mL) was added sodium azide (159 mg, 5.0 equiv., $2.45 \mathrm{mmol})$ under nitrogen atmosphere. After $5 \mathrm{~h}$ stirring at room temperature, the mixture was diluted with EtOAc and water and then extracted with EtOAc. The combined organic layer was washed with water $(5 \times 10 \mathrm{~mL})$, brine, dried over $\mathrm{MgSO}_{4}$, and concentrated in vacuo. The residue was purified by silica gel column chromatography (EtOAc/PE, 4/6) to give (E)-4Azido-3-methyl-but-2-enyl-(HDP/POC) phosphonate 14 (242 mg, 84\%) as a colorless oil. ${ }^{1} \mathrm{H} \mathrm{NMR}\left(400 \mathrm{MHz}, \mathrm{CDCl}_{3}\right) \delta 5.69-5.58\left(\mathrm{~m}, 2 \mathrm{H}, \mathrm{O}-\mathrm{CH}_{2}-\mathrm{O}\right), 5.51-5.41(\mathrm{~m}, 1 \mathrm{H}, \mathrm{CH}=\mathrm{C}), 4.91$ (sept., $\left.J=6.3 \mathrm{~Hz}, 1 \mathrm{H}, \mathrm{CH}\left(\mathrm{CH}_{3}\right)_{2}\right), 4.22-4.07\left(\mathrm{~m}, 2 \mathrm{H}, \mathrm{H}^{\mathrm{a}}\right), 3.70\left(\mathrm{~d}, J=3.9 \mathrm{~Hz}, 2 \mathrm{H}, \mathrm{CH}_{2}-\mathrm{N}_{3}\right)$, $3.46\left(\mathrm{t}, J=6.2 \mathrm{~Hz}, 2 \mathrm{H}, \mathrm{H}^{\mathrm{c}}\right), 3.37\left(\mathrm{t}, J=6.7 \mathrm{~Hz}, 2 \mathrm{H}, \mathrm{CH}_{3}\left(\mathrm{CH}_{2}\right)_{14} \mathrm{CH}_{2}-\mathrm{O}\right), 2.68(\mathrm{dd}, J=22.7$, $7.7 \mathrm{~Hz}, 2 \mathrm{H}, \mathrm{CH}_{2}-\mathrm{P}$ ), 1.90 (quint., $\left.J=6.3 \mathrm{~Hz}, 2 \mathrm{H}, \mathrm{H}^{\mathrm{b}}\right), 1.73\left(\mathrm{~d}, J=4.3 \mathrm{~Hz}, 3 \mathrm{H}, \mathrm{CH}_{3}\right), 1.53$ (quint., $\left.J=7.0 \mathrm{~Hz}, 2 \mathrm{H}, \mathrm{CH}_{3}\left(\mathrm{CH}_{2}\right)_{13} \mathrm{CH}_{2} \mathrm{CH}_{2}-\mathrm{O}\right), 1.32-1.22\left(\mathrm{~m}, 32 \mathrm{H}, \mathrm{CH}_{3}\left(\mathrm{CH}_{2}\right)_{13} \mathrm{CH}_{2} \mathrm{CH}_{2}-\mathrm{O}\right.$, $\left.\mathrm{CH}\left(\mathrm{CH}_{3}\right)_{2}\right), 0.86\left(\mathrm{t}, \mathrm{J}=6.7 \mathrm{~Hz}, 3 \mathrm{H}, \mathrm{CH}_{3}\left(\mathrm{CH}_{2}\right)_{15} \mathrm{O}\right) .{ }^{13} \mathrm{C} \mathrm{NMR}\left(100 \mathrm{MHz}, \mathrm{CDCl}_{3}\right) \delta 153.3$ $(\mathrm{C}=\mathrm{O}), 135.4,135.3(\mathrm{CH}=\mathrm{C}), 117.3,117.2(\mathrm{CH}=\mathrm{C}), 84.5,84.4\left(\mathrm{O}-\mathrm{CH}_{2}-\mathrm{O}\right), 73.1\left(\mathrm{CH}\left(\mathrm{CH}_{3}\right)_{2}\right)$, $71.2\left(\mathrm{CH}_{3}\left(\mathrm{CH}_{2}\right)_{14} \mathrm{CH}_{2}-\mathrm{O}\right), 66.5\left(\mathrm{C}^{\mathrm{c}}\right), 63.5,63.4\left(\mathrm{C}^{\mathrm{a}}\right), 58.7,58.6\left(\mathrm{CH}_{2}-\mathrm{N}_{3}\right), 32.0,30.8,30.7$

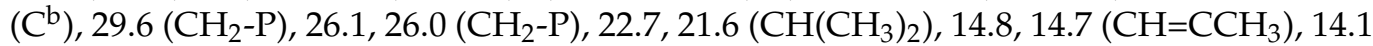
$\left(\mathrm{CH}_{3}\left(\mathrm{CH}_{2}\right)_{15} \mathrm{O}\right) .{ }^{31} \mathrm{P} \mathrm{NMR}\left(162 \mathrm{MHz}, \mathrm{CDCl}_{3}\right) \delta$ 27.80. IR $v_{\max }\left(\right.$ neat, $\left.\mathrm{cm}^{-1}\right): 2922.60,2851.80$, 2094.55, 1755.94, 1460.42, 1257.26, 1100.26, 1047.93, 992.52, $949.43 \mathrm{~cm}^{-1}$. HRMS (ESI): $\mathrm{m} / z$ $[\mathrm{M}+\mathrm{H}]^{+}$calcd for $\mathrm{C}_{29} \mathrm{H}_{57} \mathrm{~N}_{3} \mathrm{O}_{7} \mathrm{P}: 590.392864$, found: 590.393411 .

General Procedure B for Huisgen 1,3-dipolar cycloaddition

To a solution of terminal alkyne (1.3 equiv.) and (E)-4-Azido-3-methyl-but-2-enyl(HDP / POC) phosphonate 14 (1.0 equiv.) in $t \mathrm{BuOH} / \mathrm{H}_{2} \mathrm{O}(2: 1)$ were added sodium ascorbate (0.6 equiv.) and $\mathrm{CuSO}_{4} .5 \mathrm{H}_{2} \mathrm{O}$ (0.1 equiv.). The resulting suspension was stirred at $40{ }^{\circ} \mathrm{C}$ until completion (followed by TLC), then the crude mixture was co-evaporated five times with methanol. The residue was purified by silica gel column chromatography using an elution gradient of petroleum ether/ethyl acetate to give the desired HDP/POC phosphonate derivatives.

[3-Hexadecyloxypropoxy-[(E)-3-methyl-4-[4-(4-propylphenyl]triazol-1-yl]but-2-enyl] phosphoryl]oxymethyl isopropyl carbonate (15a) 
The title compound was prepared from $14(123 \mathrm{mg}, 0.21 \mathrm{mmol})$ and 1-ethynyl-4propylbenzene ( $43 \mu \mathrm{L} \mathrm{mg}, 0.27 \mathrm{mmol}$ ) following the general procedure $\mathrm{B}$; the resulting suspension was stirred for $2 \mathrm{~h}$ at $40{ }^{\circ} \mathrm{C}$. After purification on a silica gel column chromatography (EtOAc/PE, 4/6), the desired pure compound 15a (104 mg, 68\%) was obtained as a colorless oil. ${ }^{1} \mathrm{H}$ NMR $\left(400 \mathrm{MHz}, \mathrm{CDCl}_{3}\right) \delta 7.75\left(\mathrm{~s}, 1 \mathrm{H}, \mathrm{H}^{5}\right), 7.73\left(\mathrm{~s}, 2 \mathrm{H}, \mathrm{H}^{\mathrm{Ar}}\right), 7.22$ $\left(\mathrm{d}, J=8.0 \mathrm{~Hz}, 2 \mathrm{H}, \mathrm{H}^{\mathrm{Ar}}\right), 5.70-5.56\left(\mathrm{~m}, 3 \mathrm{H}, \mathrm{O}-\mathrm{CH}_{2}-\mathrm{O} ; 1 \mathrm{H}, \mathrm{CH}=\mathrm{C}\right), 4.94\left(\mathrm{~s}, 2 \mathrm{H}, \mathrm{CH}_{2}-\mathrm{N}\right)$, 4.89 (sept., $\left.J=6.3 \mathrm{~Hz}, 1 \mathrm{H}, \mathrm{CH}\left(\mathrm{CH}_{3}\right)_{2}\right), 4.22-4.11\left(\mathrm{~m}, 2 \mathrm{H}, \mathrm{H}^{\mathrm{a}}\right), 3.44\left(\mathrm{t}, J=6.1 \mathrm{~Hz}, 2 \mathrm{H}, \mathrm{H}^{\mathrm{c}}\right)$, $3.35\left(\mathrm{t}, J=6.7 \mathrm{~Hz}, 2 \mathrm{H}, \mathrm{CH}_{3}\left(\mathrm{CH}_{2}\right)_{14} \mathrm{CH}_{2}-\mathrm{O}\right), 2.73\left(\mathrm{dd}, J=22.8,7.8 \mathrm{~Hz}, 2 \mathrm{H}, \mathrm{CH}_{2}-\mathrm{P}\right), 2.60$ $\left(\mathrm{t}, J=7.5 \mathrm{~Hz}, 2 \mathrm{H}, \mathrm{Ar}-\mathrm{CH}_{2} \mathrm{CH}_{2} \mathrm{CH}_{3}\right), 1.90$ (quint., $\left.J=6.3 \mathrm{~Hz}, 2 \mathrm{H}, \mathrm{H}^{\mathrm{b}}\right), 1.68-1.63(\mathrm{~m}, 3 \mathrm{H}$, $\mathrm{CH}_{3} ; 2 \mathrm{H}, \mathrm{CH}_{2} \mathrm{CH}_{2} \mathrm{CH}_{3}$ ), 1.52 (quint., $J=7.0 \mathrm{~Hz}, 2 \mathrm{H}, \mathrm{CH}_{3}\left(\mathrm{CH}_{2}\right)_{13} \mathrm{CH}_{2} \mathrm{CH}_{2}-\mathrm{O}$ ), $1.29-1.25$ $\left(\mathrm{m}, 32 \mathrm{H}, \mathrm{CH}_{3}\left(\mathrm{CH}_{2}\right)_{13} \mathrm{CH}_{2} \mathrm{CH}_{2}-\mathrm{O}, \mathrm{CH}\left(\mathrm{CH}_{3}\right)_{2}\right), 0.95\left(\mathrm{t}, J=7.3 \mathrm{~Hz}, 3 \mathrm{H}, \mathrm{CH}_{2} \mathrm{CH}_{2} \mathrm{CH}_{3}\right), 0.88(\mathrm{t}$, $\left.J=7.0 \mathrm{~Hz}, 3 \mathrm{H}, \mathrm{CH}_{3}\left(\mathrm{CH}_{2}\right)_{15} \mathrm{O}\right) .{ }^{13} \mathrm{C}$ NMR $\left(101 \mathrm{MHz}, \mathrm{CDCl}_{3}\right) \delta 153.3(\mathrm{C}=\mathrm{O}), 148.3\left(\mathrm{C}^{\mathrm{q}}, \mathrm{Ar}\right)$, $142.8\left(\mathrm{C}^{\mathrm{q}, \mathrm{Ar}}\right), 128.9\left(\mathrm{CH}^{\mathrm{Ar}}\right), 128.0(\mathrm{CH}=\mathrm{C}), 125.6\left(\mathrm{CH}^{\mathrm{Ar}}\right), 118.9(\mathrm{CH}=\mathrm{C}), 118.8\left(\mathrm{CH}^{\mathrm{Ar}}\right), 84.4$ $\left(\mathrm{O}-\mathrm{CH}_{2}-\mathrm{O}\right)$, $73.2\left(\mathrm{CH}\left(\mathrm{CH}_{3}\right)_{2}\right), 71.2\left(\mathrm{CH}_{3}\left(\mathrm{CH}_{2}\right)_{14} \mathrm{CH}_{2}-\mathrm{O}\right), 66.4\left(\mathrm{C}^{\mathrm{c}}\right), 63.5\left(\mathrm{C}^{\mathrm{a}}\right), 57.9\left(\mathrm{CH}_{2}-\right.$ $\mathrm{N})$, 37.8 $\left(\mathrm{ArCH}_{2} \mathrm{CH}_{2} \mathrm{CH}_{3}\right), 31.9,30.7\left(\mathrm{C}^{\mathrm{b}}\right), 29.6\left(\mathrm{CH}_{2}-\mathrm{P}\right), 24.5\left(\mathrm{ArCH}_{2} \mathrm{CH}_{2} \mathrm{CH}_{3}\right)$, 22.7, 21.6, $21.5\left(\mathrm{CH}\left(\mathrm{CH}_{3}\right)_{2}\right), 14.3\left(\mathrm{C}=\mathrm{CCH}_{3}\right), 14.1\left(\mathrm{CH}_{3}\left(\mathrm{CH}_{2}\right)_{15} \mathrm{O}\right), 13.7\left(\mathrm{ArCH}_{2} \mathrm{CH}_{2} \mathrm{CH}_{3}\right) .{ }^{31} \mathrm{P}$ NMR $\left(162 \mathrm{MHz}, \mathrm{CDCl}_{3}\right) \delta$ 27.46. HRMS (ESI): $m / z[\mathrm{M}+\mathrm{H}]^{+}$calcd for $\mathrm{C}_{40} \mathrm{H}_{69} \mathrm{~N}_{3} \mathrm{NaO}_{7} \mathrm{P}: 734.486765$, found: 734.486600 .

[3-Hexadecyloxypropoxy-[(E)-3-methyl-4-[4-(4-pentylphenyl)triazol-1-yl]but-2-enyl] phosphoryl]oxymethyl isopropyl carbonate (15c)

The title compound was prepared from $14(93 \mathrm{mg}, 0.16 \mathrm{mmol})$ and 1-ethynyl-4penthylbenzene $(40 \mu \mathrm{L}, 0.21 \mathrm{mmol})$ following the general procedure $\mathrm{B}$; the resulting suspension was stirred for $2 \mathrm{~h}$ at $40{ }^{\circ} \mathrm{C}$. After purification on a silica gel column chromatography (EtOAc/PE, 4/6), the desired pure compound 15c ( $89 \mathrm{mg}, 74 \%)$ was obtained as a colorless oil. ${ }^{1} \mathrm{H} \mathrm{NMR}\left(400 \mathrm{MHz}, \mathrm{CDCl}_{3}\right) \delta 7.74\left(\mathrm{~d}, J=3.8 \mathrm{~Hz}, 2 \mathrm{H}, \mathrm{H}^{\mathrm{Ar}}\right), 7.73\left(\mathrm{~s}, 1 \mathrm{H}, \mathrm{H}^{5}\right)$, $7.22\left(\mathrm{~d}, J=8.0 \mathrm{~Hz}, 2 \mathrm{H}, \mathrm{H}^{\mathrm{Ar}}\right), 5.70-5.56\left(\mathrm{~m}, 3 \mathrm{H}, \mathrm{O}-\mathrm{CH}_{2}-\mathrm{O} ; 1 \mathrm{H}, \mathrm{CH}=\mathrm{C}\right), 4.94\left(\mathrm{~s}, 2 \mathrm{H}, \mathrm{CH}_{2}-\mathrm{N}\right)$, 4.90 (sept., $\left.J=6.2 \mathrm{~Hz}, 1 \mathrm{H}, \mathrm{CH}\left(\mathrm{CH}_{3}\right)_{2}\right), 4.22-4.11\left(\mathrm{~m}, 2 \mathrm{H}, \mathrm{H}^{\mathrm{a}}\right), 3.44\left(\mathrm{t}, J=6.1 \mathrm{~Hz}, 2 \mathrm{H}, \mathrm{H}^{\mathrm{c}}\right)$, $3.35\left(\mathrm{t}, J=6.7 \mathrm{~Hz}, 2 \mathrm{H}, \mathrm{CH}_{3}\left(\mathrm{CH}_{2}\right)_{14} \mathrm{CH}_{2}-\mathrm{O}\right), 2.73\left(\mathrm{dd}, J=22.8,7.8 \mathrm{~Hz}, 2 \mathrm{H}, \mathrm{CH}_{2}-\mathrm{P}\right), 2.62(\mathrm{t}$, $\left.J=7.8 \mathrm{~Hz}, 2 \mathrm{H}, \mathrm{Ar}-\mathrm{CH}_{2}\left(\mathrm{CH}_{2}\right)_{3} \mathrm{CH}_{3}\right), 1.90$ (quint., $\left.J=6.3 \mathrm{~Hz}, 2 \mathrm{H}, \mathrm{H}^{\mathrm{b}}\right), 1.65-1.61\left(\mathrm{~m}, 5 \mathrm{H}, \mathrm{CH}_{3}\right.$, Ar- $\mathrm{CH}_{2} \mathrm{CH}_{2} \mathrm{CH}_{2} \mathrm{CH}_{2} \mathrm{CH}_{3}$ ), 1.52 (quint., $J=7.0 \mathrm{~Hz}, 2 \mathrm{H}, \mathrm{CH}_{3}\left(\mathrm{CH}_{2}\right)_{13} \mathrm{CH}_{2} \mathrm{CH}_{2}-\mathrm{O}$ ), 1.29-1.25 $\left(\mathrm{m}, 36 \mathrm{H}, \mathrm{CH}_{3}\left(\mathrm{CH}_{2}\right)_{13} \mathrm{CH}_{2} \mathrm{CH}_{2}-\mathrm{O}, \mathrm{CH}\left(\mathrm{CH}_{3}\right)_{2}, \mathrm{Ar}-\mathrm{CH}_{2} \mathrm{CH}_{2} \mathrm{CH}_{2} \mathrm{CH}_{2} \mathrm{CH}_{3}\right), 0.88(\mathrm{t}, J=6.9 \mathrm{~Hz}$, $\left.6 \mathrm{H}, \mathrm{Ar}-\left(\mathrm{CH}_{2}\right)_{4} \mathrm{CH}_{3}, \mathrm{CH}_{3}\left(\mathrm{CH}_{2}\right){ }_{15} \mathrm{O}\right) .{ }^{13} \mathrm{C}$ NMR $\left(101 \mathrm{MHz}, \mathrm{CDCl}_{3}\right) \delta 153.2(\mathrm{C}=\mathrm{O}), 148.4,148.3$ $\left(\mathrm{C}^{\mathrm{q}, \mathrm{Ar}}\right), 143.1\left(\mathrm{C}^{\mathrm{q}}, \mathrm{Ar}\right), 135.2,135.0\left(\mathrm{C}^{\mathrm{q}, \mathrm{Ar}}\right), 128.8\left(\mathrm{CH}^{\mathrm{Ar}}\right), 127.9(\mathrm{CH}=\mathrm{C}), 125.6\left(\mathrm{CH}^{\mathrm{Ar}}\right), 118.9$ $(\mathrm{CH}=\mathrm{C}), 118.8\left(\mathrm{CH}^{\mathrm{Ar}}\right), 84.4\left(\mathrm{O}-\mathrm{CH}_{2}-\mathrm{O}\right), 73.2\left(\mathrm{CH}\left(\mathrm{CH}_{3}\right)_{2}\right), 71.2\left(\mathrm{CH}_{3}\left(\mathrm{CH}_{2}\right)_{14} \mathrm{CH}_{2}-\mathrm{O}\right), 66.4$ $\left(\mathrm{C}^{\mathrm{c}}\right), 63.6\left(\mathrm{C}^{\mathrm{a}}\right), 57.8\left(\mathrm{CH}_{2}-\mathrm{N}\right), 35.7\left(\mathrm{Ar}-\mathrm{CH}_{2}\left(\mathrm{CH}_{2}\right)_{3} \mathrm{CH}_{3}\right), 31.9,31.5,31.1,30.8,30.7\left(\mathrm{C}^{\mathrm{b}}\right), 29.8$, 29.7, 29.6, 29.5, 29.4, $26.2\left(\mathrm{CH}_{2}-\mathrm{P}\right), 22.7,22.5,21.6,21.5\left(\mathrm{CH}\left(\mathrm{CH}_{3}\right)_{2}\right), 14.3,14.2\left(\mathrm{C}=\mathrm{CCH}_{3}\right)$, 14.1 $\left(\mathrm{CH}_{3}\left(\mathrm{CH}_{2}\right)_{15} \mathrm{O}\right), 14.0\left(\mathrm{Ar}-\left(\mathrm{CH}_{2}\right)_{4} \mathrm{CH}_{3}\right) .{ }^{31} \mathrm{P}$ NMR $\left(162 \mathrm{MHz}, \mathrm{CDCl}_{3}\right) \delta$ 27.56. HRMS (ESI): $m / z[\mathrm{M}+\mathrm{Na}]^{+}$calcd for $\mathrm{C}_{42} \mathrm{H}_{72} \mathrm{~N}_{3} \mathrm{NaO}_{7} \mathrm{P}: 784.500009$, found: 784.499917.

[3-Hexadecyloxypropoxy-[(E)-3-methyl-4-[4-(heptylphenyl)triazol-1-yl]but-2-enyl] phosphoryl]oxymethyl isopropyl carbonate (15e)

The title compound was prepared from $14(113 \mathrm{mg}, 0.19 \mathrm{mmol})$ and 1-ethynyl-4heptylbenzene ( $56 \mu \mathrm{L}, 0.25 \mathrm{mmol}$ ) following the general procedure $B$; the resulting suspension was stirred for $2 \mathrm{~h}$ at $40{ }^{\circ} \mathrm{C}$. After purification on a silica gel column chromatography (EtOAc/PE, 4/6), the desired pure compound 15e $(118 \mathrm{mg}, 78 \%)$ was obtained as a colorless oil. ${ }^{1} \mathrm{H}$ NMR $\left(400 \mathrm{MHz}, \mathrm{CDCl}_{3}\right) \delta 7.73\left(\mathrm{t}, J=3.9 \mathrm{~Hz}, 3 \mathrm{H}, \mathrm{H}^{\mathrm{Ar}}, \mathrm{H}^{5}\right), 7.22(\mathrm{~d}, J=8.0 \mathrm{~Hz}, 2 \mathrm{H}$, $\left.\mathrm{H}^{\mathrm{Ar}}\right), 5.70-5.60\left(\mathrm{~m}, 3 \mathrm{H}, \mathrm{O}-\mathrm{CH}_{2}-\mathrm{O} ; 1 \mathrm{H}, \mathrm{CH}=\mathrm{C}\right), 4.94\left(\mathrm{~s}, 2 \mathrm{H}, \mathrm{CH}_{2}-\mathrm{N}\right), 4.89$ (sept., $J=6.3 \mathrm{~Hz}$, $\left.1 \mathrm{H}, \mathrm{CH}\left(\mathrm{CH}_{3}\right)_{2}\right), 4.20-4.11\left(\mathrm{~m}, 2 \mathrm{H}, \mathrm{H}^{\mathrm{a}}\right), 3.43\left(\mathrm{t}, J=6.1 \mathrm{~Hz}, 2 \mathrm{H}, \mathrm{H}^{\mathrm{c}}\right), 3.35(\mathrm{t}, J=6.7 \mathrm{~Hz}$, $\left.2 \mathrm{H}, \mathrm{CH}_{3}\left(\mathrm{CH}_{2}\right)_{14} \mathrm{CH}_{2}-\mathrm{O}\right), 2.73\left(\mathrm{dd}, J=22.8,7.8 \mathrm{~Hz}, 2 \mathrm{H}, \mathrm{CH}_{2}-\mathrm{P}\right), 2.63(\mathrm{t}, J=7.8 \mathrm{~Hz}, 2 \mathrm{H}$, Ar- $\left.\mathrm{CH}_{2}\left(\mathrm{CH}_{2}\right)_{5} \mathrm{CH}_{3}\right), 1.90$ (quint., $\left.J=6.3 \mathrm{~Hz}, 2 \mathrm{H}, \mathrm{H}^{\mathrm{b}}\right), 1.65\left(\mathrm{~d}, J=4.1 \mathrm{~Hz}, 3 \mathrm{H}, \mathrm{C}=\mathrm{CCH}_{3}\right), 1.60$ (quint., $\left.J=7.2, \mathrm{Ar}-\mathrm{CH}_{2} \mathrm{CH}_{2}\left(\mathrm{CH}_{2}\right)_{4} \mathrm{CH}_{3}\right), 1.52$ (quint., $J=7.0 \mathrm{~Hz}, 2 \mathrm{H}, \mathrm{CH}_{3}\left(\mathrm{CH}_{2}\right)_{13} \mathrm{CH}_{2} \mathrm{CH}_{2}$ O), 1.29-1.25 (m, $\left.40 \mathrm{H}, \mathrm{CH}_{3}\left(\mathrm{CH}_{2}\right)_{13} \mathrm{CH}_{2} \mathrm{CH}_{2}-\mathrm{O}, \mathrm{CH}\left(\mathrm{CH}_{3}\right)_{2}, \mathrm{Ar}-\mathrm{CH}_{2} \mathrm{CH}_{2}\left(\mathrm{CH}_{2}\right)_{4} \mathrm{CH}_{3}\right), 0.93$ (t, $\left.J=7.3 \mathrm{~Hz}, 3 \mathrm{H}, \mathrm{Ar}-\left(\mathrm{CH}_{2}\right)_{6} \mathrm{CH}_{3}\right), 0.88\left(\mathrm{t}, J=6.7 \mathrm{~Hz}, 3 \mathrm{H}, \mathrm{CH}_{3}\left(\mathrm{CH}_{2}\right){ }_{15} \mathrm{O}\right) .{ }^{13} \mathrm{C} \mathrm{NMR}(101 \mathrm{MHz}$, $\left.\mathrm{CDCl}_{3}\right) \delta 153.3(\mathrm{C}=\mathrm{O}), 143.5\left(\mathrm{C}^{\mathrm{q}, \mathrm{Ar}}\right), 135.2\left(\mathrm{C}^{\mathrm{q}, \mathrm{Ar}}\right), 135.1\left(\mathrm{C}^{\mathrm{q}, \mathrm{Ar}}\right), 129.5,129.3\left(\left(\mathrm{CH}^{\mathrm{Ar}}\right), 128.8\right.$ $\left(\mathrm{CH}^{\mathrm{Ar}}\right), 127.9(\mathrm{CH}=\mathrm{C}), 125.6\left(\mathrm{CH}^{\mathrm{Ar}}\right), 118.9(\mathrm{CH}=\mathrm{C}), 84.5,84.4\left(\mathrm{O}-\mathrm{CH}_{2}-\mathrm{O}\right), 73.3\left(\mathrm{CH}\left(\mathrm{CH}_{3}\right)_{2}\right)$, 
$71.2\left(\mathrm{CH}_{3}\left(\mathrm{CH}_{2}\right){ }_{14} \mathrm{CH}_{2}-\mathrm{O}\right), 66.4\left(\mathrm{C}^{\mathrm{c}}\right), 63.6,63.5\left(\mathrm{C}^{\mathrm{a}}\right), 57.8\left(\mathrm{CH}_{2}-\mathrm{N}\right), 35.4\left(\mathrm{Ar}-\mathrm{CH}_{2}\left(\mathrm{CH}_{2}\right)_{5} \mathrm{CH}_{3}\right)$, 33.5, 32.0, 31.4, 30.8, 30.7 (C $\left.\mathrm{C}^{\mathrm{b}}\right), 30.2,29.7,29.7,29.6,29.6,29.5,29.4,27.6,26.2\left(\mathrm{CH}_{2}-\mathrm{P}\right), 22.7$, 22.3, 21.6, $21.6\left(\mathrm{CH}\left(\mathrm{CH}_{3}\right)_{2}\right), 14.3\left(\mathrm{C}=\mathrm{CCH}_{3}\right), 14.1\left(\mathrm{CH}_{3}\left(\mathrm{CH}_{2}\right)_{15} \mathrm{O}\right), 13.9\left(\mathrm{Ar}-\left(\mathrm{CH}_{2}\right)_{6} \mathrm{CH}_{3}\right)$. ${ }^{31} \mathrm{P} \mathrm{NMR}\left(162 \mathrm{MHz}, \mathrm{CDCl}_{3}\right) \delta 27.49$. HRMS (ESI): $m / z[\mathrm{M}+\mathrm{H}]^{+}$calcd for $\mathrm{C}_{44} \mathrm{H}_{77} \mathrm{~N}_{3} \mathrm{O}_{7} \mathrm{P}$ : 790.549365, found: 790.549322 .

[[(E)-4-(4-Carbamoyltriazol-1-yl)-3-methyl-but-2-enyl]-(3-hexadecyloxypropoxy)phosphoryl]oxymethyl isopropyl carbonate $\mathbf{( 1 5 j )}$

The title compound was prepared from $14(166 \mathrm{mg}, 0.28 \mathrm{mmol})$ and propiolamide ( $25 \mathrm{mg}, 0.37 \mathrm{mmol}$ ) following the general procedure B; the resulting suspension was stirred for $18 \mathrm{~h}$ at $40{ }^{\circ} \mathrm{C}$. After purification on a silica gel column chromatography $\left(\mathrm{MeOH} / \mathrm{CH}_{2} \mathrm{Cl}_{2}\right.$, 3/97), the desired pure compound $\mathbf{1 5} \mathbf{j}(130 \mathrm{mg}, 70 \%)$ was obtained as a colorless oil. ${ }^{1} \mathrm{H}$ NMR (400 MHz, CDCl $) \delta 8.07\left(\mathrm{~s}, 1 \mathrm{H}, \mathrm{H}^{5}\right), 7.05\left(\mathrm{~s}, 1 \mathrm{H}, \mathrm{NH}_{2}\right), 5.76\left(\mathrm{~s}, 1 \mathrm{H}, \mathrm{NH}_{2}\right), 5.69-5.58$ (m, 2H, O-CH $\left.-\mathrm{CH}_{2} \mathrm{O} 1 \mathrm{H}, \mathrm{CH}=\mathrm{C}\right), 4.94-4.91\left(\mathrm{~m}, 2 \mathrm{H}, \mathrm{CH}_{2}-\mathrm{N} ; 1 \mathrm{H}, \mathrm{CH}\left(\mathrm{CH}_{3}\right)_{2}\right), 4.22-4.12(\mathrm{~m}, 2 \mathrm{H}$, $\left.\mathrm{H}^{\mathrm{a}}\right), 3.46\left(\mathrm{t}, J=6.1 \mathrm{~Hz}, 2 \mathrm{H}, \mathrm{H}^{\mathrm{c}}\right), 3.37\left(\mathrm{t}, J=6.7 \mathrm{~Hz}, 2 \mathrm{H}, \mathrm{CH}_{3}\left(\mathrm{CH}_{2}\right)_{14} \mathrm{CH}_{2}-\mathrm{O}\right), 2.71(\mathrm{dd}, J=22.9$, $\left.7.8 \mathrm{~Hz}, 2 \mathrm{H}, \mathrm{CH}_{2}-\mathrm{P}\right), 1.90$ (quint., $\left.J=6.3 \mathrm{~Hz}, 2 \mathrm{H}, \mathrm{H}^{\mathrm{b}}\right), 1.62\left(\mathrm{~d}, J=4.4 \mathrm{~Hz}, 3 \mathrm{H}, \mathrm{C}=\mathrm{CCH}_{3}\right), 1.52$ (quint., $\left.J=7.0 \mathrm{~Hz}, 2 \mathrm{H}, \mathrm{CH}_{3}\left(\mathrm{CH}_{2}\right)_{13} \mathrm{CH}_{2} \mathrm{CH}_{2}-\mathrm{O}\right), 1.31-1.24\left(\mathrm{~m}, 32 \mathrm{H}, \mathrm{CH}_{3}\left(\mathrm{CH}_{2}\right)_{13} \mathrm{CH}_{2} \mathrm{CH}_{2}-\mathrm{O}\right.$, $\left.\mathrm{CH}\left(\mathrm{CH}_{3}\right)_{2}\right), 0.87\left(\mathrm{t}, \mathrm{J}=7.0 \mathrm{~Hz}, 3 \mathrm{H}, \mathrm{CH}_{3}\left(\mathrm{CH}_{2}\right){ }_{15} \mathrm{O}\right) .{ }^{13} \mathrm{C} \mathrm{NMR}\left(101 \mathrm{MHz}, \mathrm{CDCl}_{3}\right) \delta 161.8$ $\left(\mathrm{NH}_{2} \mathrm{C}=\mathrm{O}\right), 153.2(\mathrm{C}=\mathrm{O}), 143.1\left(\mathrm{C}^{\mathrm{q}, \mathrm{Ar}}\right), 134.2,134.1(\mathrm{CH}=\mathrm{C}), 125.6\left(\mathrm{CH}^{\mathrm{Ar}}\right), 120.1,120.0$ $(\mathrm{CH}=\mathrm{C}), 84.5,84.4\left(\mathrm{O}-\mathrm{CH}_{2}-\mathrm{O}\right), 73.2\left(\mathrm{CH}\left(\mathrm{CH}_{3}\right)_{2}\right), 71.3\left(\mathrm{CH}_{3}\left(\mathrm{CH}_{2}\right)_{14} \mathrm{CH}_{2}-\mathrm{O}\right), 66.4\left(\mathrm{C}^{\mathrm{C}}\right), 63.6$, $63.5\left(\mathrm{C}^{\mathrm{a}}\right), 58.2,58.1\left(\mathrm{CH}_{2}-\mathrm{N}\right), 31.9,30.8,30.7\left(\mathrm{C}^{\mathrm{b}}\right), 29.7,29.6,29.6,29.6,29.5,29.3,27.6,26.2$, $26.1\left(\mathrm{CH}_{2}-\mathrm{P}\right), 22.7,21.6\left(\mathrm{CH}\left(\mathrm{CH}_{3}\right)_{2}\right), 14.3,14.2\left(\mathrm{C}=\mathrm{CCH}_{3}\right), 14.1\left(\mathrm{CH}_{3}\left(\mathrm{CH}_{2}\right)_{15} \mathrm{O}\right) .{ }^{31} \mathrm{P} \mathrm{NMR}$ $\left(162 \mathrm{MHz}, \mathrm{CDCl}_{3}\right) \delta$ 27.11. HRMS (ESI): $m / z[\mathrm{M}+\mathrm{H}]^{+}$calcd for $\mathrm{C}_{32} \mathrm{H}_{60} \mathrm{~N}_{4} \mathrm{O}_{8} \mathrm{P}: 659.414328$, found: 659.414346 .

[3-Hexadecyloxypropoxy-[(E)-3-methyl-4-[4-(nitrophenyl)triazol-1-yl]but-2-enyl]phosphoryl]oxymethyl isopropyl carbonate (151)

The title compound was prepared from $14(115 \mathrm{mg}, 0.20 \mathrm{mmol})$ and 1-ethynyl-4nitrobenzene ( $37 \mathrm{mg}, 0.25 \mathrm{mmol}$ ) following the general procedure $\mathrm{B}$; the resulting suspension was stirred for $3 \mathrm{~h}$ at $40{ }^{\circ} \mathrm{C}$. After purification on a silica gel column chromatography (EtOAc/PE, 5/5), the desired pure compound 151 (102 mg, 71\%) was obtained as a colorless oil. ${ }^{1} \mathrm{H}$ NMR $\left(400 \mathrm{MHz} \mathrm{CDCl}_{3}\right) \delta 8.27\left(\mathrm{~d}, J=8.8 \mathrm{~Hz}, 2 \mathrm{H}, \mathrm{H}^{\mathrm{Ar}}\right), 8.01(\mathrm{~d}, J=8.9 \mathrm{~Hz}$, $\left.2 \mathrm{H}, \mathrm{H}^{\mathrm{Ar}}\right), 7.98\left(\mathrm{~s}, 1 \mathrm{H}, \mathrm{H}^{5}\right), 5.70-5.58\left(\mathrm{~m}, 3 \mathrm{H}, \mathrm{O}-\mathrm{CH}_{2}-\mathrm{O} ; 1 \mathrm{H}, \mathrm{CH}=\mathrm{C}\right), 4.97\left(\mathrm{~s}, 2 \mathrm{H}, \mathrm{CH}_{2}-\mathrm{N}\right)$, 4.89 (sept., $\left.J=6.3 \mathrm{~Hz}, 1 \mathrm{H}, \mathrm{CH}\left(\mathrm{CH}_{3}\right)_{2}\right), 4.22-4.11\left(\mathrm{~m}, 2 \mathrm{H}, \mathrm{H}^{\mathrm{a}}\right), 3.44\left(\mathrm{t}, J=6.2 \mathrm{~Hz}, 2 \mathrm{H}, \mathrm{H}^{\mathrm{c}}\right)$, $3.35\left(\mathrm{t}, J=6.6 \mathrm{~Hz}, 2 \mathrm{H}, \mathrm{CH}_{3}\left(\mathrm{CH}_{2}\right)_{14} \mathrm{CH}_{2}-\mathrm{O}\right), 2.73\left(\mathrm{dd}, J=22.8,7.8 \mathrm{~Hz}, 2 \mathrm{H}, \mathrm{CH}_{2}-\mathrm{P}\right), 1.90$ (quint., $J=6.2 \mathrm{~Hz}, 2 \mathrm{H}, \mathrm{H}^{\mathrm{b}}$ ), $1.66\left(\mathrm{~d}, J=4.4 \mathrm{~Hz}, 3 \mathrm{H}, \mathrm{C}=\mathrm{CCH}_{3}\right), 1.52$ (quint., $J=7.0 \mathrm{~Hz}, 2 \mathrm{H}$, $\left.\mathrm{CH}_{3}\left(\mathrm{CH}_{2}\right)_{13} \mathrm{CH}_{2} \mathrm{CH}_{2}-\mathrm{O}\right), 1.27-1.23\left(\mathrm{~m}, 32 \mathrm{H}, \mathrm{CH}_{3}\left(\mathrm{CH}_{2}\right)_{13} \mathrm{CH}_{2} \mathrm{CH}_{2}-\mathrm{O}, \mathrm{CH}\left(\mathrm{CH}_{3}\right)_{2}\right), 0.86(\mathrm{t}$, $\left.J=7.0 \mathrm{~Hz}, 3 \mathrm{H}, \mathrm{CH}_{3}\left(\mathrm{CH}_{2}\right){ }_{15} \mathrm{O}\right) .{ }^{13} \mathrm{C} \mathrm{NMR}\left(101 \mathrm{MHz}, \mathrm{CDCl}_{3}\right) \delta 153.2(\mathrm{C}=\mathrm{O}), 147.3\left(\mathrm{C}^{\mathrm{q}, \mathrm{Ar}}\right)$, $146.0\left(\mathrm{C}^{\mathrm{q}, \mathrm{Ar}}\right), 136.9\left(\mathrm{C}^{\mathrm{q}, \mathrm{Ar}}\right), 134.7,134.5(\mathrm{CH}=\mathrm{C}), 126.1\left(\mathrm{CH}^{\mathrm{Ar}}\right), 124.3\left(\mathrm{CH}^{\mathrm{Ar}}\right), 121.0\left(\mathrm{CH}^{\mathrm{Ar}}\right)$, 119.8, $119.7(\mathrm{CH}=\mathrm{C}), 84.4,84.3\left(\mathrm{O}-\mathrm{CH}_{2}-\mathrm{O}\right), 73.3,73.1\left(\mathrm{CH}\left(\mathrm{CH}_{3}\right)_{2}\right), 71.2\left(\mathrm{CH}_{3}\left(\mathrm{CH}_{2}\right)_{14} \mathrm{CH}_{2}-\mathrm{O}\right)$, 66.5, $66.3\left(\mathrm{C}^{\mathrm{c}}\right)$, 63.6, $63.5\left(\mathrm{C}^{\mathrm{a}}\right)$, 58.1, $58.0\left(\mathrm{CH}_{2}-\mathrm{N}\right), 31.9,30.8,30.7\left(\mathrm{C}^{\mathrm{b}}\right), 29.7,29.6,29.6$, 29.6, 29.5, 29.5, 29.3, 27.5, 26.1, $26.1\left(\mathrm{CH}_{2}-\mathrm{P}\right), 22.7,21.6,21.6,21.6\left(\mathrm{CH}\left(\mathrm{CH}_{3}\right)_{2}\right), 14.4,14.3$ $\left(\mathrm{C}=\mathrm{CCH}_{3}\right), 14.1\left(\mathrm{CH}_{3}\left(\mathrm{CH}_{2}\right){ }_{15} \mathrm{O}\right) .{ }^{31} \mathrm{P} \mathrm{NMR}\left(162 \mathrm{MHz}, \mathrm{CDCl}_{3}\right) \delta 27.31$. HRMS (ESI): $\mathrm{m} / z$ $[\mathrm{M}+\mathrm{Na}]^{+}$calcd for $\mathrm{C}_{37} \mathrm{H}_{61} \mathrm{~N}_{4} \mathrm{NaO}_{9} \mathrm{P}: 759.406837$, found: 759.406817 .

\section{Conclusions}

In summary, we have efficiently synthesized various hitherto unknown ANP prodrugs bearing the (E)-2'-methyl-but-2' -enyl aliphatic side-chain with 1,4-substituted-1,2,3-triazoles as nucleobase. The convergent synthesis was based on olefin acyclic cross-metathesis and $\mathrm{CuAAC}$ cross-coupling reaction as the key steps. All those compounds were evaluated against HBV, HIV and SARS-CoV-2 viruses for their antiviral properties. Among them, compound 15j, a HDP/POC prodrug with $\mathrm{R}=\mathrm{C}(\mathrm{O}) \mathrm{NH}_{2}$, a ribavirin analog, showed $62 \%$ inhibition (at $10 \mu \mathrm{M}$ ) without significant cytotoxicity $\left(\mathrm{IC}_{50} 66.4 \mu \mathrm{M}\right.$ in HepG2 cells and $\mathrm{IC}_{50}=43.1 \mu \mathrm{M}$ in HepG2 cells). Further structural optimization of both the (E)-2'-methylbut-2'-enyl aliphatic side-chain and the heterocycle is underway, alongside more detailed 
biological testing of the most active compound, with the aim of improving further its antiviral potency.

Supplementary Materials: The following are available online at https: / www.mdpi.com/1420-30 49/26/5/1493/s1, 1H-,13C-, 31P- and NOESY NMR spectra of all synthetized molecules.

Author Contributions: Conceptualization, V.R. and L.A.A.; chemistry of all compounds, T.A.; biological evaluation on HBV, J.M., C.G.-G., D.B., T.R.M. and R.F.S.; biological evaluation on SARS-CoV-2, C.B., F.T., B.C.; writing-original draft preparation, T.A., V.R., L.A.A.; supervision, L.A.A. and V.R. All authors have read and agreed to the published version of the manuscript.

Funding: T. Abuduaini thanks the China Scholarship Council for the PhD fellowship. We thank L. Bassit and O. Russell (from Pr. Raymond F. Schinazi's laboratory) for the biological evaluations. R.F.S. is supported in part by NIH grant P30AI050409. L.A.A. thanks the LABEX SynOrg (ANR-11LABX-0029) for support.

Conflicts of Interest: No potential conflict of interest was reported by the authors.

Sample Availability: Samples of the compounds are available on request from the corresponding authors.

\section{References}

1. Krečmerová, M. Nucleoside and nucleotide analogues for the treatment of herpesvirus infections: Current stage and new prospects in the field of acyclic nucleoside phosphonates. In Herpesviridae-A Look into This Unique Family of Viruses; Magel, F.D., Ed.; IntechOpen Limited: London, UK, 2012; pp. 245-270, ISBN 978-953-51-0186-4.

2. Holý, A. Current Protocols in Nucleic Acid Chemistry; Synthesis of acyclic nucleoside phosphonates. Unit 14.2; John Wiley \& Sons, Inc.: Hoboken, NJ, USA, 2005.

3. De Clercq, E.; Holý, A. Acyclic nucleoside phosphonates: A key class of antiviral drugs. Nat. Rev. Drug Discov. 2005, 4, 928-940. [CrossRef] [PubMed]

4. De Clercq, E. Acyclic nucleoside phosphonates: An unfinished story. Collect. Czech. Chem. Commun. 2011, 76, 480-506. [CrossRef]

5. Wiemer, A.J.; Wiemer, D.F. Prodrugs of phosphonates and phosphates: Crossing the membrane barrier. Top. Curr. Chem. 2015, 360, 115-160.

6. Farquhar, D.; Srivastva, D.N.; Kattesch, N.J.; Saunders, P.P. Biologically reversible phosphate-protective groups. J. Pharm. Sci. 1983, 72, 324-325. [CrossRef] [PubMed]

7. Srivastva, D.N.; Farquhar, D. Bioreversible phosphate protective groups-Synthesis and stability of model acyloxymethyl phosphates. Bioorg. Chem. 1984, 12, 118-129. [CrossRef]

8. Naesens, L.; Bischofberger, N.; Augustijns, P.; Annaert, P.; Van den Mooter, G.; Arimilli, M.N.; Kim, C.U.; De Clercq, E. Antiretroviral efficacy and pharmacokinetics of oral bis(isopropyloxycarbonyloxymethyl)-9-(2-phosphonylmethoxypropyl)adenine in mice. Antimicrob. Agents Chemother. 1998, 42, 1568-1573. [CrossRef]

9. Hostetler, K.Y. Alkoxyalkyl prodrugs of acyclic nucleoside phosphonates enhance oral antiviral activity and reduce toxicity: Current state of the art. Antiviral. Res. 2009, 82, A84-A98. [CrossRef]

10. Ballatore, C.; McGuigan, C.; De Clercq, E.; Balzarini, J. Synthesis and evaluation of novel amidate prodrugs of PMEA and PMPA. Bioorg. Med. Chem. Lett. 2001, 11, 1053-1056. [CrossRef]

11. McGuigan, C.; Hassan-Abdallah, A.; Srinivasan, S.; Wang, Y.; Siddiqui, A.; Daluge, S.M.; Gudmundsson, K.S.; Zhou, H.; McLean, E.W.; Peckham, J.P.; et al. Application of phosphoramidate ProTide technology significantly improves antiviral potency of carbocyclic adenosine derivatives. J. Med. Chem. 2006, 49, 7215-7226. [CrossRef]

12. Topalis, D.; Pradère, U.; Roy, V.; Caillat, C.; Azouzi, A.; Broggi, J.; Snoeck, R.; Andrei, G.; Lin, J.; Eriksson, S.; et al. Novel antiviral C5-substituted pyrimidine acyclic nucleoside phosphonates selected as human thymidylate kinase substrates. J. Med. Chem. 2011, 54, 222-232. [CrossRef]

13. Montagu, A.; Pradere, U.; Roy, V.; Nolan, S.P.; Agrofoglio, L.A. Expeditious convergent procedure for the preparation of bis(POC) prodrugs of new (E)-4-phosphono-but-2-en-1-yl nucleosides. Tetrahedron 2011, 67, 5319-5328. [CrossRef]

14. Pradère, U.; Clavier, H.; Roy, V.; Nolan, S.P.; Agrofoglio, L.A. The shortest strategy for generating phosphonate prodrugs by olefin cross metathesis-application to acyclonucleoside phosphonates. Eur. J. Org. Chem. 2011, 36, 7324-7330. [CrossRef]

15. Hamada, M.; Roy, V.; McBrayer, T.R.; Whitaker, T.; Urbina-Blanco, C.; Nolan, S.P.; Balzarini, J.; Snoeck, R.; Andrei, G.; Schinazi, R.F.; et al. Synthesis and broad spectrum antiviral evaluation of bis(POM) prodrugs of novel acyclic nucleosides. Eur. J. Med. Chem. 2013, 67, 398-408. [CrossRef]

16. Amblard, F.; Cho, J.H.; Schinazi, R.F. The Cu(I)-catalyzed Huisgen azide-alkyne 1,3-dipolar cycloaddition reaction in nucleoside, nucleotide and oligonucleotide chemistry. Chem. Rev. 2009, 109, 4207-4220. [CrossRef] [PubMed]

17. Bessières, M.; Hervin, V.; Roy, V.; Chartier, A.; Snoeck, R.; Andrei, G.; Lohier, J.-F.; Agrofoglio, L.A. Highly convergent synthesis and antiviral activity of $€$-but-2-enyl nucleoside phosphonoamidates. Eur. J. Med. Chem. 2018, 25, 678-686. [CrossRef] [PubMed]

18. Tornøe, C.W.; Christensen, C.; Meldal, M. Peptidotriazoles on solid phase: $[1,2,3]$-triazoles by regiospecific copper(i)-catalyzed 1,3-dipolar cycloadditions of terminal alkynes to azides. J. Org. Chem. 2002, 67, 3057-3064. [CrossRef] [PubMed] 
19. Rostovtsev, V.V.; Green, L.G.; Fokin, V.V.; Sharpless, K.B. A Stepwise Huisgen Cycloaddition Process: Copper(I)—Catalyzed Regioselective "Ligation" of Azides and Terminal Alkynes. Angew. Chem. Int. Ed. 2002, 41, 2565-2568. [CrossRef]

20. Zheng, H.; McDonald, R.; Hall, D.G. Boronic acid catalysis for mild and selective [3+2] dipolar cycloadditions to unsaturated carboxylic acids. Chem. Eur. J. 2010, 16, 5454-5460. [CrossRef]

21. Langley, D.R.; Walsh, A.W.; Baldick, C.J.; Eggers, B.J.; Rose, R.E.; Levine, S.M.; Kapur, J.; Colonno, R.J.; Tenney, D.J. Inhibition of hepatitis B virus polymerase by entecavir. J. Virol. 2007, 81, 3992-4001. [CrossRef] [PubMed]

22. Marlet, J.; Lier, C.; Roch, E.; Maugey, M.; Moreau, A.; Combe, B.; Lefeuvre, S.; d'Alteroche, L.; Barbereau, D.; Causse, X.; et al. Revisiting HBV resistance to entecavir with a phenotypic approach. Antiviral Res. 2020, 181, 104869. [CrossRef]

23. Ladner, S.K.; Otto, M.J.; Barker, C.S.; Zaifert, K.; Wang, G.H.; Guo, J.T.; Seeger, C.; King, R.W. Inducible expression of human hepatitis B virus (HBV) in stably transfected hepatoblastoma cells: A novel system for screening potential inhibitors of HBV replication. Antimicrob. Agents Chemother. 1997, 41, 1715-1720. [CrossRef]

24. Stuyver, L.J.; Lostia, S.; Adams, M.; Mathew, J.S.; Pai, B.S.; Grier, J.; Tharnish, P.M.; Choi, Y.; Chong, Y.; Choo, H.; et al. Antiviral activities and cellular toxicities of modified 2', $3^{\prime}$-dideoxy-2',3'-didehydrocytidine analogues. Antimicrob. Agents Chemother. 2002, 46, 3854-3860. [CrossRef] [PubMed]

25. Schinazi, R.F.; Sommadossi, J.P.; Saalmann, V.; Cannon, D.L.; Xie, M.-W.; Hart, G.C.; Smith, G.A.; Hahn, E.F. Activity of 3'-azido3'-deoxythymidine nucleotide dimers in primary lymphocytes infected with human immunodeficiency virus type 1 . Antimicrob. Agents Chemother. 1990, 34, 1061-1067. [CrossRef]

26. Schinazi, R.F.; McMillan, A.; Cannon, D.; Mathis, R.; Lloyd, R.M.; Peck, A.; Sommadossi, J.-P.; St Clair, M.; Wilson, J.; Furman, P.A. Selective inhibition of human immunodeficiency viruses by racemates and enantiomers of cis-5-fluoro-1-[2-(hydroxymethyl)-1,3oxathiolan-5-yl]cytosine. Antimicrob. Agents Chemother. 1992, 36, 2423-2431. [CrossRef] [PubMed]

27. Belen'kii, M.S.; Schinazi, R.F. Multiple drug effect analysis with confidence interval. Antivir. Res. 1994, 25, 1-11. [CrossRef]

28. Chou, T.-C.; Talalay, P. Quantitative analysis of dose-effect relationships: The combined effects of multiple drugs or enzyme inhibitors. Adv. Enzyme Regul. 1984, 22, 27-55. [CrossRef] 